\title{
Manifestaciones de la facies esquemática en el centro y norte de la Península Ibérica *
}

\author{
Juan A. Gomez-Barrera **
}

Con la publicación en 1935 del primero de los cuatro volúmenes que compondrian la magna obra del Abate $\mathrm{H}$. Breuil sobre las pinturas rupestres esquemáticas de la Peninsula lbérica, se generalizó el uso del término "arte esquemático" para definir aquellas manifestaciones artisticas, ora trazadas en pintura ora en grabado, cuyas caracteristicas básicas pasaban por la abstracción esquemática de gran parte de sus motivos. El "Simposio Internacional de Arte Rupestre» de Barcelona sirvió para que Ripoll (1966) estableciera nuevas pautas cronológicas de estas formas artísticas a la vez que las incluia dentro de lo que él denominó Arte Rupestre Postpaleolítico. Acosta, en 1968, reinterpretó los trabajos de Breuil, estableció categorias tipológicas y cronológicas y diseñó los conceptos "esquematismo" y "fenómeno esquemático" que aún hoy, pese a diferentes matizaciones de la propia autora y de otros investigadores, siguen siendo válidos.

Todos estos trabajos despertaron un gran interés entre los arqueólogos y prehistoriadores hispanos y en los últimos años se han dado a conocer cientos de nuevos grupos - pintados y grabados- de estas muestras artísticas, han proliferado los estudios parciales, locales y regionales e, incluso, se han vuelto a replantear to acertado o no del término, los ciclos artísticos que englobaria, su origen y cronologia y con ellos toda su interpretación.

* Texto de la lección dictada por el autor en el curso “Introducción al Arte Rupestre Prehistórico de la Peninsula lbérica" (viernes 12 de julio de 1991), dentro del programa de "Cursos de Verano" de la UNED (Ávila) y bajo la dirección del Prof. Dr. D. Eduardo Ripoll Perelló.

** Dr. en Prehistoria y Catedrático de Geografia e Historia del I. B. de Almazán (Soria) 
A las criticas conceptuales y aportaciones cronológicas del arte esquemático andaluz propugnadas por la "escuela granadina» (CARRAsco et alii, 1982 y 1983), siguió la celebración de la II Reunión de Prehistoria Aragonesa (Barbastro, 1987) donde un representativo grupo de investigadores del arte rupestre peninsular abordó, como tema monográfico del encuentro, los «problemas terminológicos y conceptuales que actualmente tiene planteados la investigación de las expresiones pictóricas" - $y$ grabadas, añadimos nosotros - «encuadrables cronológicamente en un momento posterior al desarrollo del arte parietal de época paleolítica» (BALDELLOU 1989). La nomenclaruta propuesta por estos especialistas acoge dentro del llamado arte postpaleolítico a cinco grandes grupos artísticos que a su vez concentran en si otros subgrupos o ciclos tal y como a continuación se expone: 1. Arte Epipaleolitico, subdividido según los tipos de industria en Aziliense y Epipaleolítico microlaminar y geométrico; 2. Arte de Petracos que definiría al arte macroesquemático o contestano; 3. Arte Levantino, son sus variantes estilisticas naturalista estilizado y estilazado-esquemático; 4. Arte Esquemático, distinguiendo entre un arte esquemático tipico distribuido por toda la Peninsula y con sus grafismos bien conocidos y definidos y un arte esquemático de tendencia geométrica y otro de tendencia naturalista. Finalmente establecen un quinto grupo bajo el epigrafe de Otros Artes que reunia los tipos singulares del Arte del Tajo de las Figuras, Arte megalitico (en el que se incluye al Arte de las estelas de época megalítica), Arte del NO o grabados del NO, Arte de Soria y Segovia o grabados de Soria y Segovia, Arte de Solacueva (Galeria de Silex), Arte del Tajo o grabados del Tajo, Arte de las Hurdes o grabados de las Hurdes y Arte Canario.

Aun con los avances prácticos que esta clarificadora clasificación pudiera y pueda aportar parece evidente que las mayores dificultades surgen a la hora de definir y regionalizar el arte esquemático, no tanto por albergar «un conjunto de formas habitualmente no comprensibles de modo directo" - como escribiera Balbín Behrman (1989) - cuanto por incluir en él a muchas cosas diferentes hasta ahora no lo suficientemente conocidas.

Mal definido, pues, y peor regionalizado. $Y$ es que frente a la necesaria tendencia a la sintesis se hace imprescindible estudios parciales que no por serlo queden reducidos a localismos inconexos. El buen criterio del grupo de Barbastro les obliga, sin embargo, a crear un amplio cajón de sastre que no termina de desgajarse del arte esquemático y que incluye, como hemos visto, manifestaciones tan dispares como el Arte del Tajo de las Figuras, los grabados del Tajo o el Arte del NO, por lo demás de amplio conocimiento y participes de densos programas de estudio, y 
junto a ellos el mal definido Arte de Soria y Segovia o el, a nuestro juicio, incompleto Arte de Solacueva.

Es por ello por lo que estamos con Balbin cuando, a pesar de los constantes descubrimientos y múltiples publicaciones, denuncia la falta de un corpus manejable de todos los grupos artisticos, los insuficientes intentos de establecer relación material con las manifestaciones artísticas y la inexistencia de cuadros de variantes formales o de asociaciones locales de motivos, aspectos estos que de llevarse a efecto marcarian un notable avance en la investigación del arte esquemático.

Asumiendo estos planteamientos y con ellos, entendiendo primordial y previa a cualquier consideración la regionalización del fenómeno esquemático -caracterizando zonas (BÉCARES 1983) y núcleos de arte rupestre (López PAYER y SORIA LeRma 1988) - y estableciendo, con la precisión posible, el sustrato cultural de cada uno de los yacimientos, hemos estudiado en los últimos años los grabados rupestres postpaleoliticos del Alto Duero, lo que nos ha permitido diferenciar de la pintura rupestre esquemática -o Arte Esquemático Tipico- dos ciclos artisticos, grabados ambos, que se desarrollarian, el uno, en cuevas y al aire libre, el otro, y que aparecerán marcadamente diferenciados no sólo en su distribución espacial sino, también, técnica, temática y cronológicamente.

La determinación nuclear y zonal de los grabados no impidió su relación artística y arqueológica con otros de áreas más extensas y asi no fue dificil apreciar los múltiples paralelos estilisticos existentes entre las cavernas sorianas y aquellas otras que se abren por la zona nororiental y oriental de los rebordes montañosos de la Meseta Norte y su prolongación por el extremo oriental de la región cantábrica. Menor rigor se observa en las relaciones por establecer entre los grabados al aire libre del suroeste soriano y sus semejantes dispersos por toda la Peninsula, no obstante lo cual se pudo avanzar en un primer esbozo de sintesis que ayude a su caracterización.

Con estas consideraciones previas trataremos en nuestra exposición acercarnos más que a las facies esquemáticas del centro y norte de la Pensinsula a las que son propias de la Meseta Norte Española, con sus ejemplificaciones de pintura esquemática (o Arte Esquemático Típico), grabados en cuevas (Grabados en cuevas del Centro-Norte de la Península) y grabados al aire libre.

\section{LA PINTURA ESQUEMÁTICA}

Caracterizada por el marcado esquematismo de la mayoria de sus motivos, la realización de éstos a base de trazados simples de anchura no 


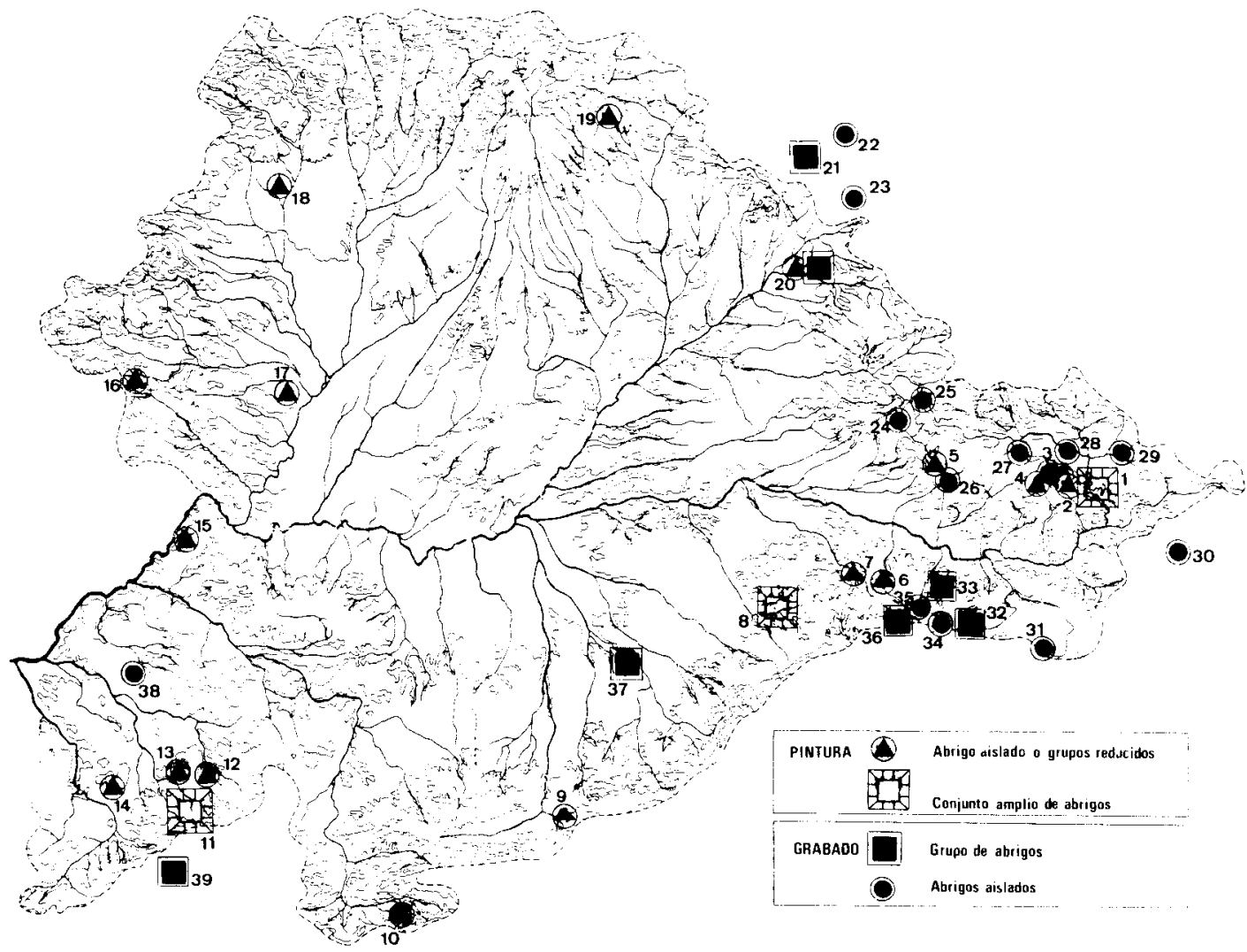

Fig. 1. Distribución del Arte rupestre postpaleolitico en la Meseta Norte española: 1. Valonsadero; 1. Pedrajas; 3. Oteruelos; 4. Fuentetoba; 5. Ucero; 6. Ligos; 7. Tierras de Ayllón; 8. Barranco del Duratón; 9. Ojos albos; 10. Raso de Candelada; 11. Las Batuecas Garcibuey; 12. Las Quilamas; 13. Peñas del Gato; 14. Bonete del Cura (Ciudad Rodrigo); 15. Palla Rubia (Pereña); 16.- Sierra de La Culebra; 17. El Castillón (Santa Eulalia de Tabara); 18. Vega de Espinareda (Sésamo); 19. Camasores (Palencia); 20. Atapuerca; 21. Ojo Guareña; 22. Cueva del Portal; 23. Cueva de Penches; 24. Cueva de San Garcia; 25. Revenga; 26. Cueva de San Bartolomé; 27. Cueva Maja; 28. Langosto; 29. Canos (Sierra del Almuerzo); 30. Covarrubias (Ciria); 31. Cueva de La Santa Cruz (Conquezuela); 32. Retolillo; 33. Manzanares-Tiermes; 34. Castro; 35. Valvenedizo; 36. Sotillos; 37. Domingo Garcia; 38. Yecla de Yeltres y 39. Las Hurdes. 
superior al grosor de los dedos, uso generalizado de la tinta plana en tonos rojos, ocres y, ocasionalmente, amarillos, negros y blancos y localización usual en abrigos y covachos a cuyas paredes - superficies lisas utilizadas como soportes- llega la luz solar, es la Pintura Rupestre Esquemática la muestra del arte prehistórico hispano más difundido - cerca del millar de estaciones-y, como ha puesto de manifiesto recientemente J. Bécares (1991), de la que tenemos la referencia escrita más antigua. A las primeras copias de pintura esquemática trazadas por D. Fernando López de Cárdenas, en 1783, en Fuencaliente (NiETo 1984) se superpone la descripción de Las Batuecas y de sus pinturas escrita por Antonio López en el tomo séptimo de su obra Viaje de España publicado en 1778.

Es precisamente en Las Batuecas donde se concentra uno de los núcleos de arte rupestre esquemático más importante, y mejor conocido, de la Meseta Norte española. Junto a él se alinean los conjuntos del Barranco del Duratón y del Monte Valonsadero y un rosario de estaciones aisladas por las provincias de Ávila, Burgos, León, Palencia, Zamora y las ya citadas de Salamanica, Segovia y Soria. Por ahora falta una análisis de conjunto y en tanto llega éste ' podremos esbozar algunas caracteristicas de los mismos a partir de sintesis y articulos de divulgación científica de las distintas estaciones.

Bécares Pérez (1974, 1976, 1980 y 1991) y Grande del Brio (1987), junto con otros colaboradores como González-Tablas, han venido sistematizando sus descubrimientos y los publicados por Breuil en 1935 y recogen en la provincia de Salamanca un total de 60 estaciones pintadas, la gran mayoria de ellas localizadas en la zona sur de la misma, en la conocida comarca de La Sierra y por tanto en la cuenca del Tajo; en la cuenca del Duero tan sólo se encuentran los abrigos de Las Peñas del Gato (Cereceda de la Sierra), Bonete del Cura (Ciudad Rodrigo) y Palla Rubia. La mayor concentración pictórica se da en Las Batuecas, núcleo que atrajo la atención de Breuil (1918-19, 1933-35), Cabré (1922) y Hernández Pacheco (1922) y del que se viene ocupando desde la década de los setenta Bécares. La utilización ele abrigos o covachos cuarcíticos, próximos a cauces de agua - arroyos o fuentes naturales-, como soportes de una pintura caracterizada por el predominio de la temática de barras y puntos

Desde 1987 se está llevando a cabo un ambicioso proyecto de investigación interdisciplinar y pluriuniversitario dirigido por la Dra. doña Soledad Corchón, Catedrática de Prehistoria de la Universidad de Salamanca, en torno a la elaboración del cInventario y estudio científico del Arte Rupestre Prehistórico de la Comunidad de Castilla-León" y que acoge la participación de los distintos especialistas y sus investigaciones en la región. Este inventario conducirá a una sintesis del tema basada en el análisis total de sus manifestaciones. 


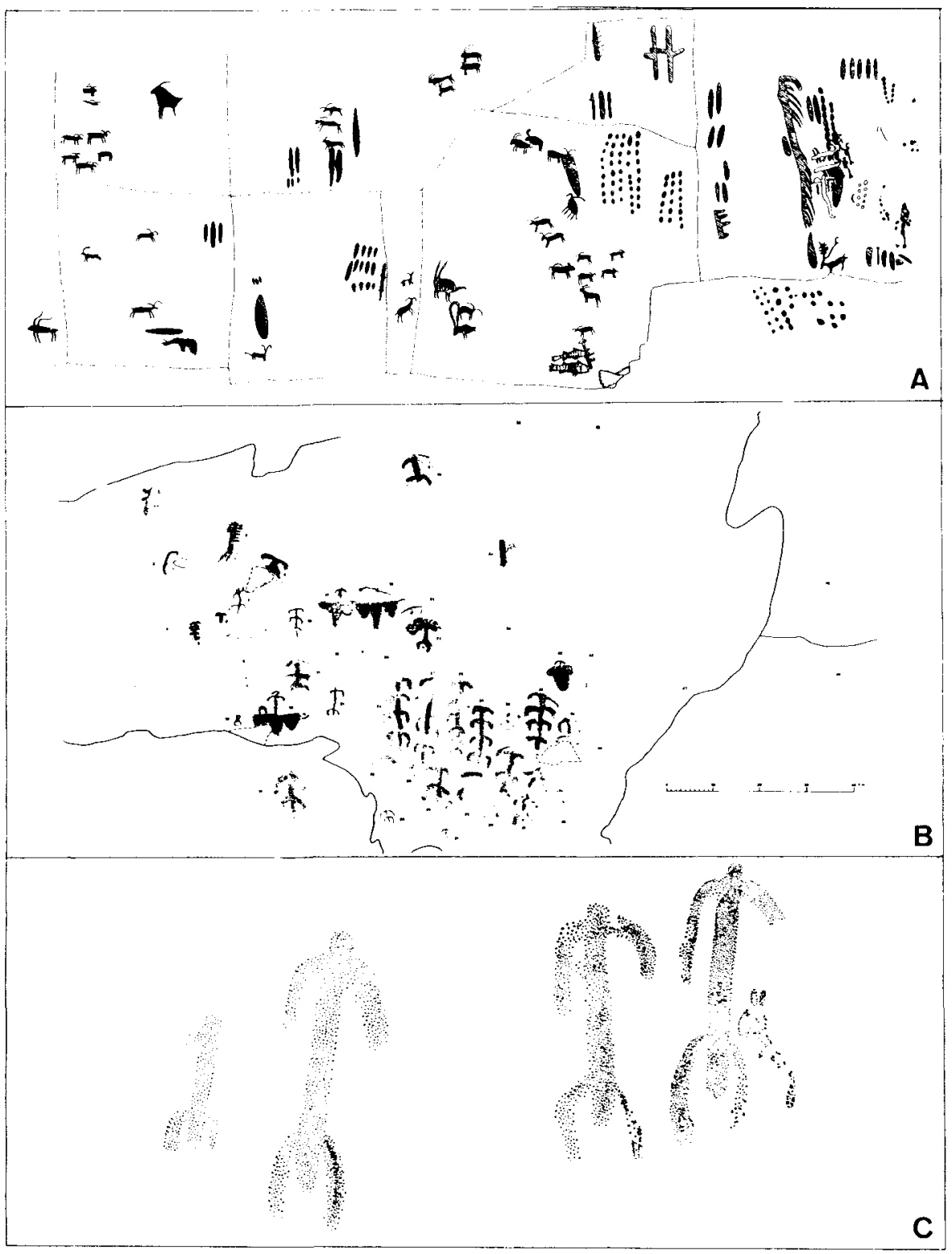

Fig. 2. Pinturas rupestres esquemáticas de Las Batuecas (A) Canchal de las Cabras Pintadas, según Breuil, 1933-35, vol. I, fig. 2, C) Corral de Morcilla, según Bécares 1991, fig. 4, y Ciudad Rodrigo (B) Bonete del Cura, según calco de Bécares, 1991, fig. 6) 
seguidos, en su frecuencia reiterativa, por antropomorfos y zoomorfos y, en menor escala, ramiformes, tecniformes, pectiniformes y soliformes determina una coincidencia básica con la pintura rupestre esquemática del resto de la Peninsula; no obstante, se pueden concretar peculiaridades propias tales como cierta tendencia naturalista en el trazado de los cuadrúpedos conformando su figura no mediante la prolongación de un simple linea dorsal a modo de cabeza, tronco y rabo y cuatro trazos descendentes y paralelos para dar cuenta de las patas sino dibujando la forma del tronco y la cabeza en tinta plana o simplemente contorneados y patas realizadas en trazo más fino y ágil (BÉCAREs 1991: 72-73). La abundancia de antropomorfos con tocados - de plumas, cuernos, bilobulados, trilobulados y orla de puntos - que sirvieron a F. Jordá (1970-71) para relacionar cronológicamente esta pintura con el Arte Levantino, la utilización de la pintura blanca (en Bonete del Cura, Cueva del Rayo de Valero, Umbría de las Torres, Los Acerones, Covacho del Pallón, Cancha de las Barras y Hoyita del Coscorrón 1) y la representación de peces (Canchales de Mahoma, Canchal de las Cabras Pintadas y Canchal de las Barras) son otras de las singularidades por destacar del conjunto salmantino.

Para González-Tablas (1980) las pinturas abulenses de Peña Mingubela (Ojos Albos) vendrian a constituir el enlace artístico entre las ricas manifestaciones esquemáticas de la Sierra de Francia y los grabados y pinturas de Domingo Garcia y Barranco del Duratón, en Segovia. El descubrimiento posterior de las pinturas del Risco de la Zorrera de El Raso de Candeleda (TERÉs 1987) y las noticias de los grupos artísticos localizados por Álvaro Bobadilla (1989) al norte de la Sierra del Guadarrama confirman aquella opinión, pareciéndonos la Fase I de Peña Mingubela claro nexo de unión entre los abrigos salmantinos, las pinturas de Candeleda y el conjunto del Duratón mientras que las Fases II, III y IV paralelizan casi con exactitud con gran parte de los motivos grabados descubiertos por Álvaro Bobadilla y el complejo mundo de Domingo Garcia.

Peña Mingubela acoge 31 conjuntos pintados en tonalidades rojizas aplicadas en tintas planas sobre trazo grueso, en las tres primeras fases, y fino, en la cuarta. Las cuatro fases observadas por González-Tablas en su ejecución insinúan una evolución estilistica prolongada que iría desde el Bronce Final hasta época medieval. La Fase I, con representaciones propias del Arte Esquemático Típico, nos llevaria al Bronce Final; la Fase II, caracterizada por la presencia de antropomorfos armados con espadas cortas y de filos rectos, apuntadas y largas, implicaria un horizonte cultural del Hierro; la aparición de figuraciones de orantes y la ausencia de superposiciones situaria la Fase III en un momento no concreto de la prerromanización de la Meseta, mientras que la Fase IV, compuesta por es- 
JUAN A. GÓMEZ-BARRERA

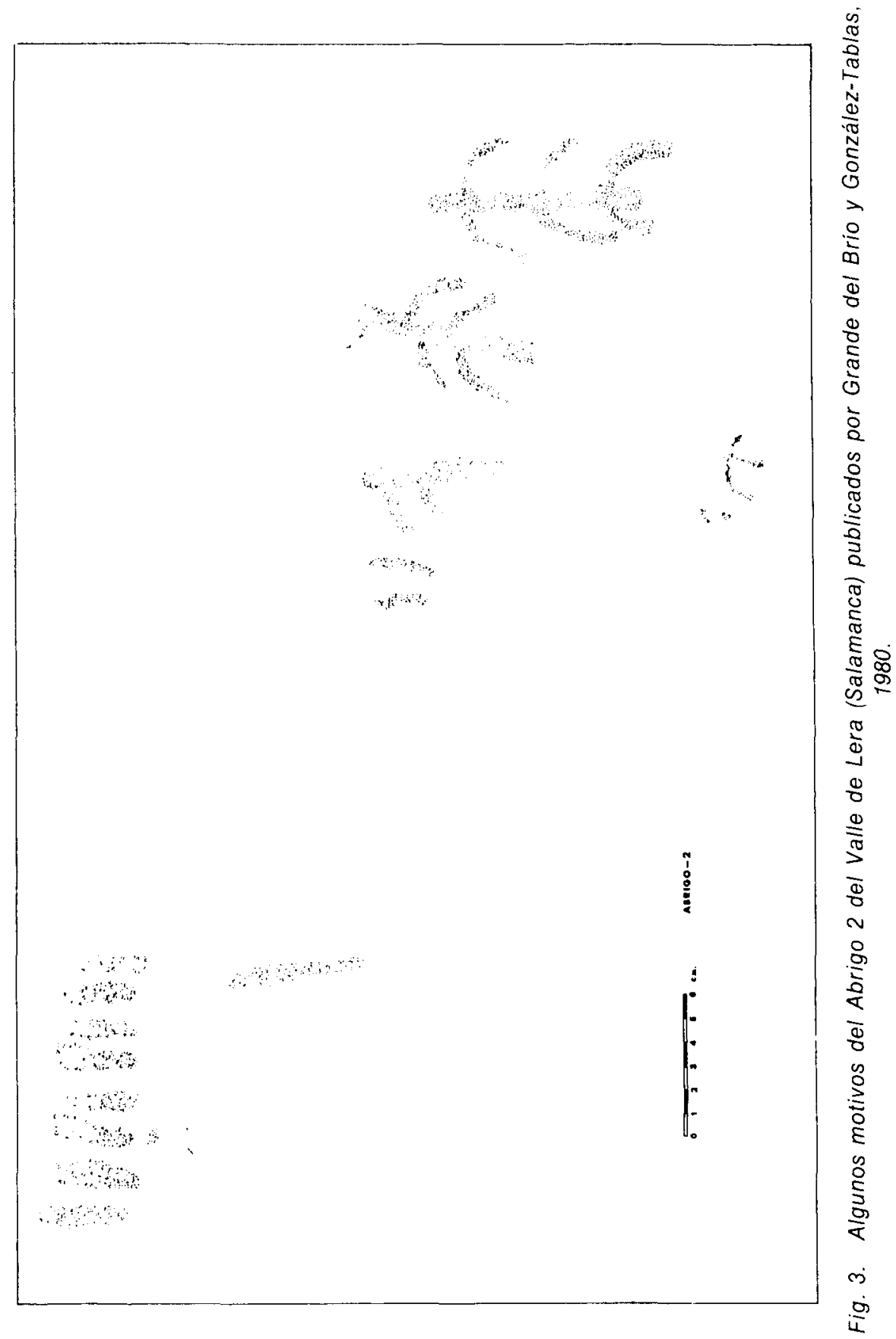


Manifestaciones de la facies esquemática en el centro ...

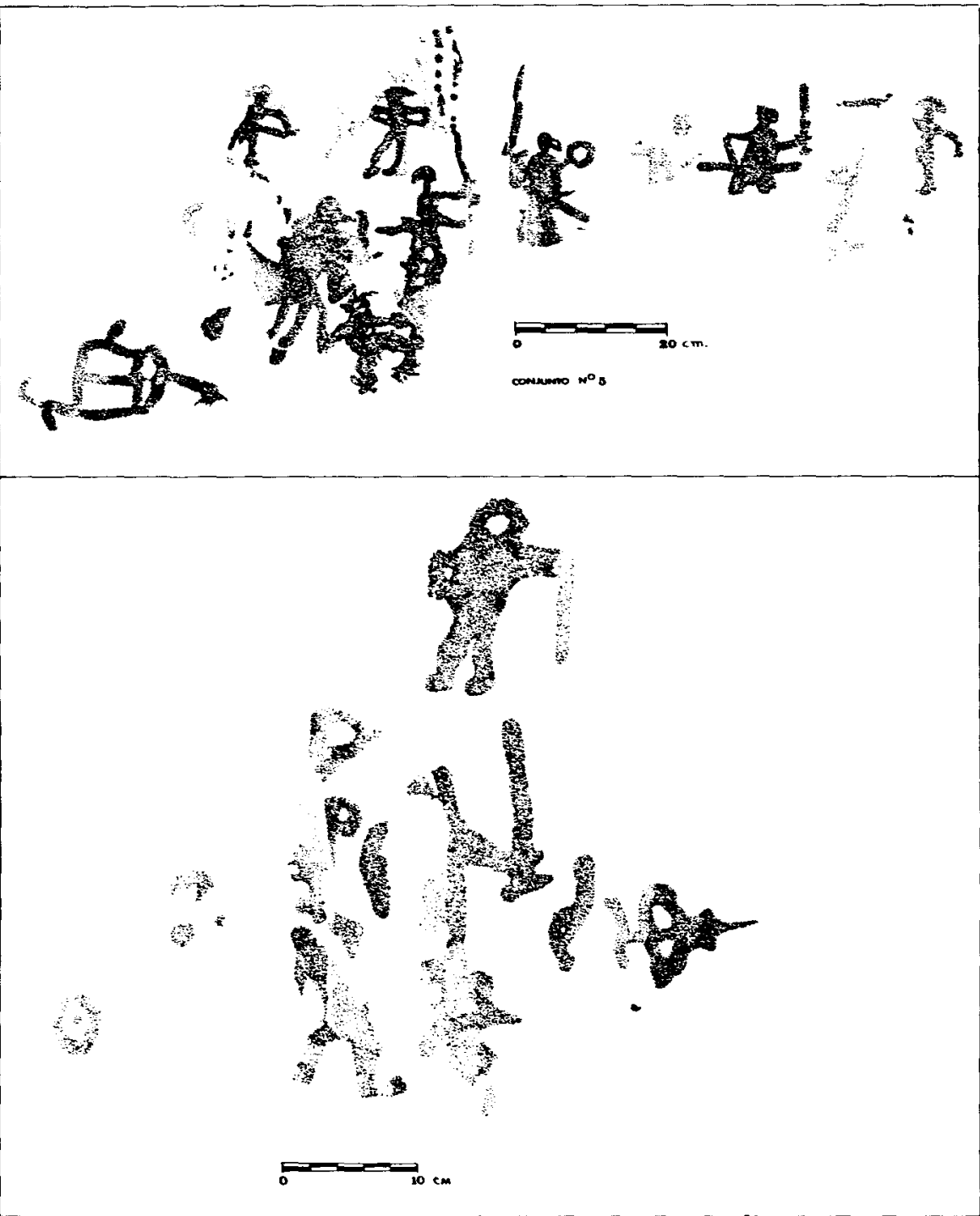

Fig. 4. Pinturas esquemáticas de Peña Mingubela, Ávila, según F. J. GonzálezTablas Sastre, 1980.

quemas de trazo fino, nos conduce al horizonte medieval anteriormente mencionado (GonzÁlEZ-TABLAS 1980: 61-62).

Las pinturas del Risco de la Zorrera, en El Raso de Candeleda, fueron descubiertas por don Antonio Morán y dadas a conocer en 1987 por $E$. 
Terés, en una nota informativa de la Revista de Arqueología. Su estudio, publicado parcialmente, se debe a A. Beltrán (1989a: 109-111 y 1989b: 149161) quien distinguió en el conjunto dos paneles verticales ( $A$ y B) cubiertos por otro horizontal (C) y tres fases en la ejecución de las pinturas, a saber: una caracterizada por trazos de color rojo anaranjado muy desvaidos, otra definida por trazos más gruesos en rojo vivo destacando un antropomorfo de cabeza radiada y gran tamaño y una tercera fase documentada por sus figuras - zoomórficas y humanas - filiformes. Datado todo el conjunto entre un Neolítico avanzado y fines de la Edad del Bronce, el propio Beltrán destaca «una estructura construida, formada por un enrejado de lineas verticales soportando otra horizontal sobre la que se apoyan figuras femeninas bitriangulares, con los brazos alzados en actitud orante", que interpreta como templo o altar e identifica con un santuario o estructura construida en madera (1989a: 112 y 1989b: 155). Es de hacer notar como en el paraje en que se localiza el covacho del Risco de la Zorrera se han hallado restos arqueológicos que denuncian la existencia de un castro de la II Edad del Hierro y, posiblemente, otro de la Edad del Bronce.

Las muestras de pintura rupestre esquemática son también abundantes en la provincia de Segovia (Lucas 1974), concentrándose de manera excepcional en los escarpes de las zonas más encajadas del Río Duratón, entre los términos de Castrillo, Villaseca, Burgomillado y Carrascal del Río. De los 26 abrigos con pinturas del Duratón se conoce en profundidad por su publicación únicamente el del Solapo del Águila (LucAs 1971), si bien R. Lucas realizó su Tesis Doctoral sobre el conjunto dando a conocer amplios avances del mismo (LucAs 1977 y 1979), lo que nos proporciona algunas características del núcleo artístico como su ubicación generalizada en abrigos o solapas, la agrupación pictórica en lugares bien definidos de las rocas (recovecos, oquedades) de clara intencionalidad artistica, el uso frecuente del color rojo con algún motivo en negro y un estilo muy variado que iria desde el subnaturalismo hasta la completa abstracción. Antropomorfos, idoliformes, cuadrúpedos, ramiformes, esteliformes, pectiniformes, estructuras, lineas paralelas, lineas curvas, puntos y barras aparecen en una frecuencia variable y coincidente en cuanto al predominio de las figuraciones humanas, esteliformes, ramiformes, cuadrúpedos, barras y puntos con la tendencia a nivel peninsular. Una cronología tardía —en torno al comienzo del primer milenio a. C. y el carácter de "recinto sagrado" atribuido a todo el barranco, son conclusiones que aporta Lucas Pellicer como definidoras del conjunto segoviano.

A través de los abrigos de Ligos entramos, en nuestro recorrido artístico-pictórico esquemático, en la provincia de Soria donde a los Abrigos del Este y del Oeste se han de unir los del Valle de Ucero (Cueva de La 
Manifestaciones de la facies esquemática en el centro ...

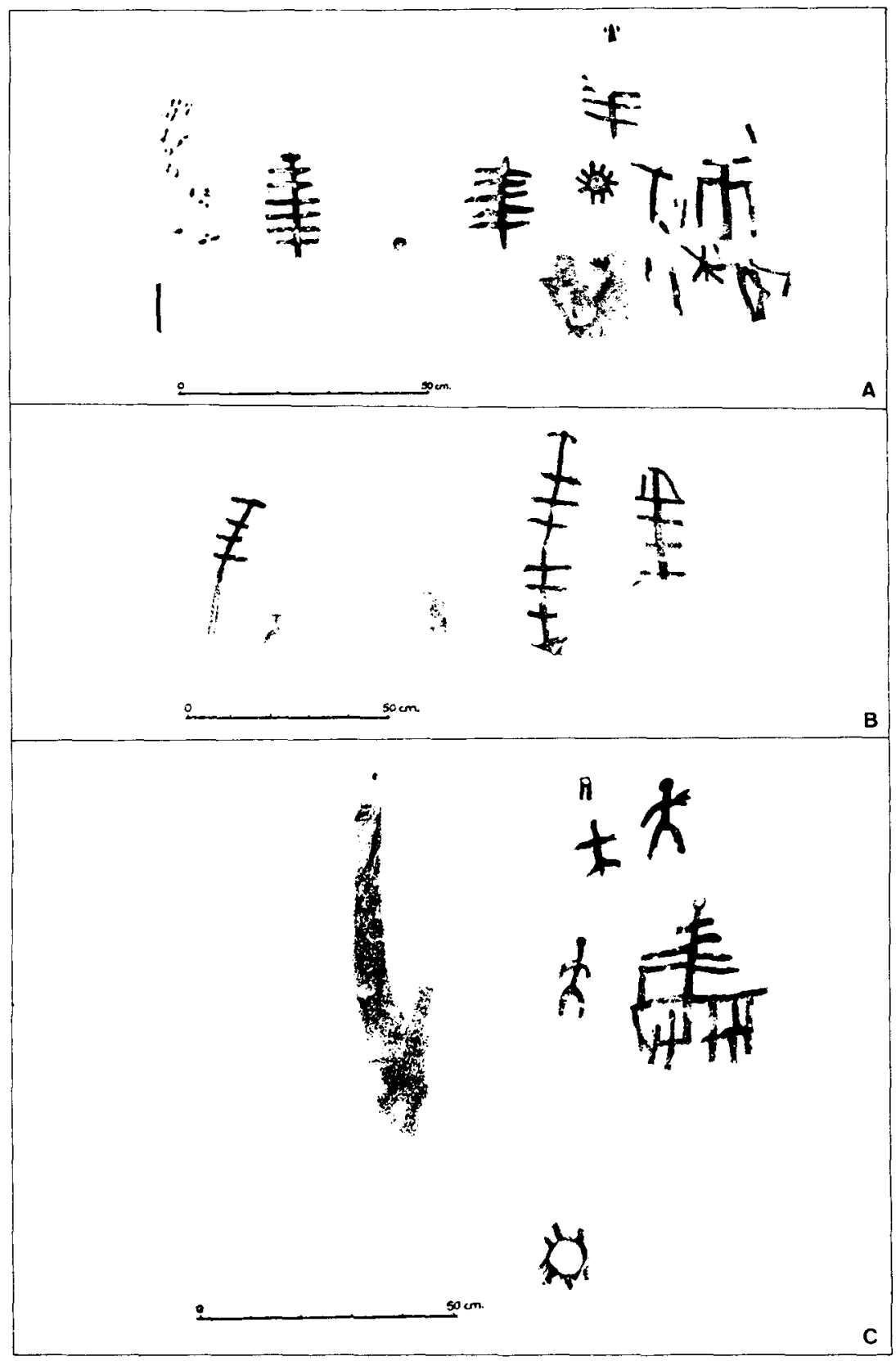

Fig. 5. Grupos 20 (A), 19 (B) y 11-12 (C) del Solapo del Águila, en el Barranco del Duratón (calcos de M. ${ }^{2}$ R. Lucas Pellicer, 1971). 
Galiana y Cueva Conejos), Fuentetoba (La Peña los Plantios), Oteruelos (Cueva Larga y Cueva Grande) y Pedrajas (Prado de Santa María) que nos conducirian a las estribaciones del Monte Valonsadero, núcleo esencial del esquematismo soriano con 31 estación localizadas. Los abrigos sorianos - superficies rocosas expuestas en su totalidad al aire librese sitúan en lugares prominentes y destacados, cerca de un rio y en zonas ricas en praderios, manchas de monte bajo, encinares y carrascales, muy apropiadas para recibir el asentamiento humano y animal al menos en épocas estivales. Los temas representados son, significativamente, variadisimos, apareciendo ocho posibles motivos ídolos - nueve, si se contabiliza el rito funerario del Abrigo del Tubo-, número muy exiguo comparado con las 149 figuras humanas y las 78 figuraciones de cuadrúpedos. Gran notoriedad adquieren, a la hora del computo conceptual y estadistico, los 52 motivos barras que, unas veces en grupo y otras más aisladas, se dibujan en la mayoria de los abrigos sorianos. El cuadro estadístico se completa con 18 motivos en zig-zag, 15 esteliformes o representaciones astrales, 19 tectiformes o, en algunos casos, construcciones, 21 grupos de puntos, 13 ramiformes, seis parejas, seis objetos identificados como armas y un amplio número de motivos que por su gran esquematización o su mal estado de conservación impiden su determinación interpretativa. Culto a los muertos, culto al sol o al toro, ceremonias rituales... podrían ser algunas de las explicaciones derivadas de las diferentes escenas y asociaciones recurrentes observadas en el conjunto esquemático soriano. Pero sin duda, lo que parece notorio, es que el predominio de la figura humana y animal está en relación directa con los modos de vida de esta gente que, se ha de suponer, serian pastores completando su régimen económico con la caza, la recolección y con el trabajo primitivo de la tierra.

En otras publicaciones (Gómez-Barrera 1982, 1983-84, 1990) se ha desarrollado más ampliamente el estudio de la pintura rupestre esquemática de la altimeseta soriana y a ellas hemos de remitir para cuestiones más pormenorizadas.

La intensidad esquemática del Sistema Central no tiene, por ahora, tan densa continuidad por el Sistema lbérico meseteño ni por las estribaciones de la Cordillera Cantábrica, limitándose a puntos aislados de las provincias de Burgos, Palencia y León.

En el momento actual de investigación la pintura rupestre-esquemática queda reducida en la provincia de Burgos a las esquematizaciones (motivos lineales y un cuadrúpedo) de la Cueva del Azar en Orbaneja del Castillo (BLANCO 1986), los signos pintados en rojo de la Cueva Mayor de Atapuerca (Breuil y Obermaier 1913: 5; Breull 1933-35: 36-37), las mues- 
tras pintadas en rojo y en negro de los tramos III y IV de la Galeria del Sílex (APELLÁnIZ y URIBARRI 1976: 167) y ejemplos aislados no bien estudiados en el karst de Ojo Guareña (ORTEGa y MARTin 1986).

En Palencia el único hallazgo es la Cueva de los Burros, en Camasobres, que si bien era conocida desde principios de siglo (Breull 193335: vol. I, pág. 37) no fue estudiada con detalle hasta 1985 en que las señoritas Mínguez Álvaro, Ramirez Díez y Ugarte Orúe realizaron su revisión publicando una amplia monografía. Para estas autoras las pinturas de Camasobres se sitúan tanto por su estilo como por su temática — centrada exclusivamente en la representación humana muy simple y esquematizada, con manchas y barras como única compañia- en un período tardio del Esquematismo.

Las pinturas esquemáticas de Peña Piñera, en Sésamo (Vega de Espinareda), son las únicas manifestaciones conocidas hasta el momento presente en León y fueron dadas a conocer en una cuidada monografia por Gutiérrez González y Avelló Álvarez (1986). Peña Piñera ofrece 351 motivos de técnica, coloración y tamaño similar al resto de los abrigos con pintura esquemática de la Peninsula lbérica, si bien presenta pequeñas particularidades que le dan un carácter especial como por ejemplo la frecuencia de figuras antropomórficas de cabeza con vacio central, el tipo humano de "orante" y la figura número 5 del conjunto $B$ que sus investigadores identifican como la representación de un carro, que daría una cronologia relativa para la estación de Sésamo en torno al segundo tercio del primer milenio a. C. A esta aportación cronológica añaden el paralelo fechable, para los ramiformes del Conjunto $F$, en un tema similar decorativo de un hacha de talón y dos anillas de Lancia datada en el Bronce Final, fecha que encuadra perfectamente con el entorno arqueológico del Bierzo.

El círculo esquemático de la Meseta Norte se cerraría con los hallazgos aislados de la provincia de Zamora: la Covacha del Portillón y el Canchal de Melendro, localizados en la Sierra de la Culebra y publicados por Grande del Brio (1982 y 1987: 115) y al Abrigo de El Castillón, en Santa Eulalia de Tabara, de reciente documentación (FERNÁNDEZ RIVERA 198 ). Los tres abrigos repiten temas en barras y antropomórficos y constituyen, por el Oeste meseteño, el puente de enlace entre las pinturas salmantinas y las leonesas.

\section{GRABADOS EN CUEVAS DEL CENTRO-NORTE DE LA PENINSULA}

Ya Garcia-Soto y Moure, al estudiar el arte rupestre de las cuevas de San Bartolomé (1984: 157) y de San Garcia (1986: 202 y 1987: 515), habian 
señalado la existencia de un horizonte cultural que posiblemente agruparia estas manifestaciones parietales extendiéndose básicamente por la zona nororiental y oriental de los rebordes montañosos de Castilla la Vieja. En concreto esta "provincia» artistica comprenderia, según los autores citados, las estaciones grabadas de Ojo Guareña y Penches al Norte de Burgos y Galeria del Silex, San Garcia, San Bartolomé de Ucero, La Griega, La Vaquera o Fuente Dura y Los Enebralejos en las serranias que se extienden entre el SE de Burgos y el NO de Segovia. Parece evidente que Cueva Maja - descubierta con posterioridad a los trabajos mencionados-, por su ubicación y caracteristicas artisticas formaria parte de este horizonte siendo más problamática la presencia de Covarrubias (Ciria) por su situación más oriental, aunque sus manifestaciones plásticas se muestren parejas.

La afinidad artistica de estos yacimientos, aparte de las coincidencias arqueológicas, fue también obvia para Municio y Piñón (1986-87: 142 y 1990: 74), Municio y Zamora (1989: 271) y para nosotros mismos (GomezBARRERA 1990: 197) produciéndose asi el diseño de una provincia artística o cuanto menos de un ciclo artístico independiente como señaló Bécares. Para este autor (1987: 92) los yacimientos aquí referidos conformarian el Ciclo de Solacueva-Galeria del Sílex, al prolongarse los yacimientos meseteños por la cabecera del Duero y parte oriental de la región cantábrica.

En nuestra Tesis Doctoral (Gomez-BarRera 1991) hemos desglosado ampliamente este tema analizando los yacimientos sorianos y todos aquellos que, a nuestro juicio, componen esta provincia artistica. Las caracteristicas generales de los yacimientos sorianos definen en buena manera las particularidades del ciclo por lo que nos detendremos en ellas no sin que ello impida un breve repaso en el contenido artístico y arqueológico de cada estación.

Presentan las cuevas sorianas —Cuevas de San Bartolomé de Ucero, Covarrubias de Ciria y Cueva Maja de Cabrejas del Pinar-sus motivos distribuidos en superficies, más o menos rugosas, bien señaladas en el recinto y visibles dentro del marco espacial que las cobija. Su temática, más cerca de la abstracción y estilización lineal y geométrica que del esquematismo cognoscible, admite un cuadro tipológico en el que es fácil distinguir figuraciones -o motivos relacionables con un modelo real, que en el caso soriano se reducen a diversas formas antropomórficas y representaciones lineales y geométricas conformando reticulas, zig-zags, anguliformes, esteliformes, arboriformes, pectiniformes, motivos lineales horizontales o verticales y marañas. Es de hacer constar la ausencia, en todas las cuevas sorianas, de la representación animal constituyendo este 
Manifestaciones de la facies esquemática en el centro ...

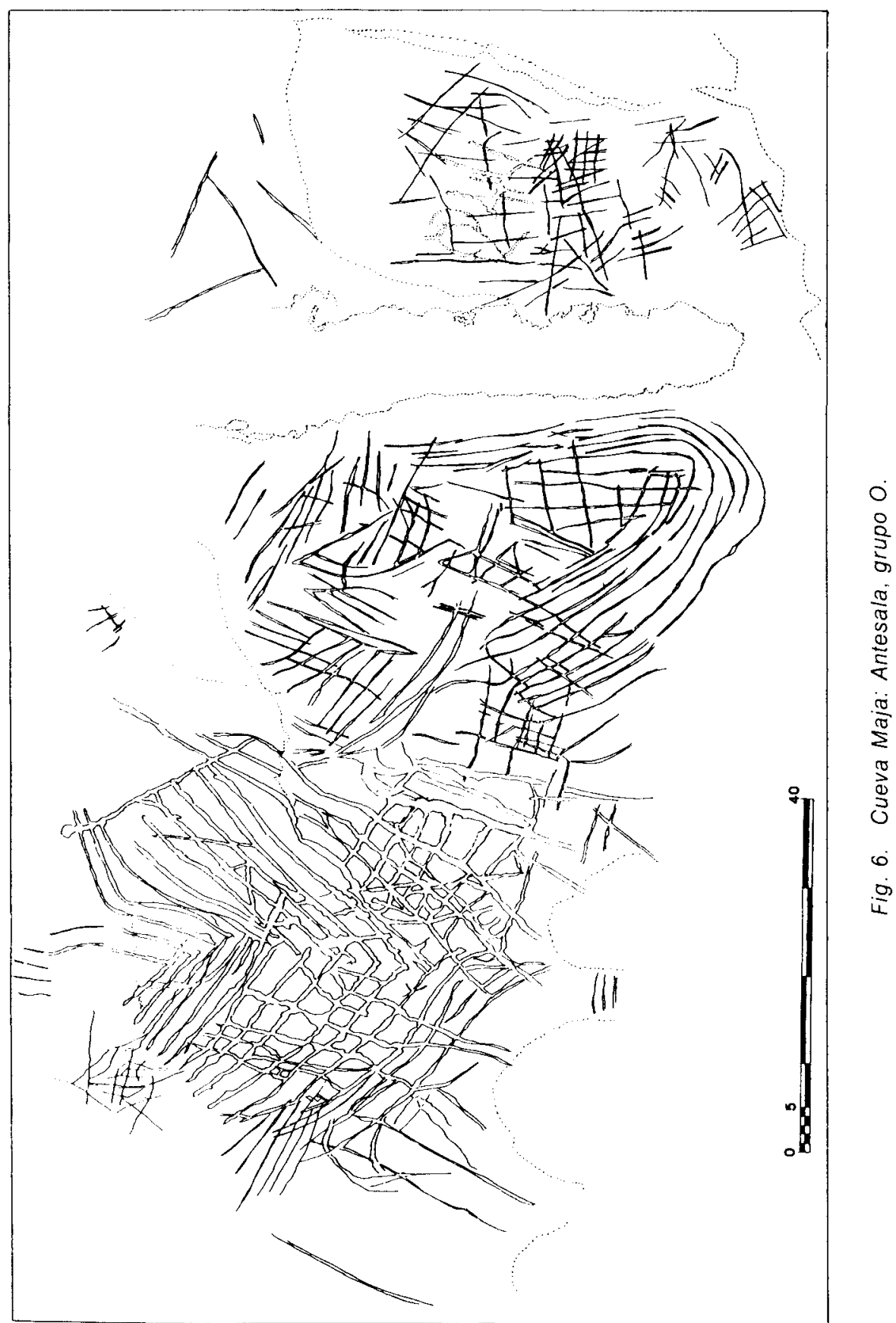


hecho, junto con la escasa repercusión de los temas figurados y la reducción de los motivos antropomórficos a zonas concretas y menos accesibles de las cavernas (Cueva Maja), una caracterización del conjunto que avalaria la interpretación simbólica y sentido cultural de estas manifestaciones. Del mismo modo, resulta de máximo interés el papel desempeñado por los motivos reticulados en Cueva Maja, cuya distribución por el recinto artistico de la cueva parece responder a una interncionalidad ritual de delimitación del espacio sagrado del yacimiento (GómEz-BARRERA, 1990b: 102-104).

Técnicamente, en las cuevas sorianas se utilizan los soporte irregulares -que ofrecen hornacinas, oquedades, coladas, vetas cóncavas diseñadas en paredes verticales o estructuras techadas- para recibir el grabado, generalmente inciso en $V$ de trazo simple único y algún ejemplo abrasivo en $U$ y utilización marginal del repiqueteado. Por lo demás y en lo hasta ahora conocido es evidente la ausencia total de huellas de pintura que pudieran señalar la coexistencia de ésta con el grabado como contrariamente, ocurre en otras cuevas de la Mesetas Norte (Los Enebralejos, La Vaquera, Galería de Silex, Kaite II y Keimada) y zona Cantábrica (Solacueva, Lazalday y Los Moros).

Tanto a través del estudio tipológico individualizado como del realizado a nivel de ciclo artístico, se ha podido poner de manifiesto los múltiples paralelos estilisticos existentes entre las cavernas sorianas y aquellas otras que se abren por la zona nororiental y oriental de los rebordes montañosos de la Meseta Norte y su prolongación por el extremo oriental de la región cantábrica. Esta provincia englobaria al menos treinta y ocho yacimientos en cuevas de las provincias de Segovia (Los Enebralejos, La Vaquera, La Griega y La Llave), Soria (Cueva Mayor y Cueva Menor de San Bartolomé de Ucero, Covarrubias de Ciria y Cueva Maja en Cabrejas del Pinar), Burgos (San Garcia, Galeria del Sílex, Cueva de Penches y Cueva de San Bernabé, Kaite II, Galeria de Chipichondo, Sala de la Fuente, Sala Cartón, Sala Keimada, Galeria de los Grabados, Galería Macarroni y Kubia en el complejo kárstico de Ojo Guareña, además de El Silo, Narices, Primate y San Pelayo), Navarra (Cueva de Basaura, en Berindano), Álava (Solacueva, Lazalday, Los moros, Liciti, P. Corral), Vizcaya (Goikolau) y Cantabria (Riva, Villegas, Brujas II, Comillas, Cirrios, Barcenaciones, Hoyos I y Cueva del Faro). Del inventario al que sometimos a estas cuevas en nuestra Tesis Doctoral podemos inferir algunos datos significativos como la utilización del grabado - generalmente inciso- en 29 de los yacimientos analizados, coexistiendo en ocho casos con la pintura y siendo ésta usada como única técnica en seis cuevas de Álava y Cantabria. Su tipología temática admite, en igual proporción a los ejemplos sorianos, la doble división de figuraciones y motivos más abstractos, 


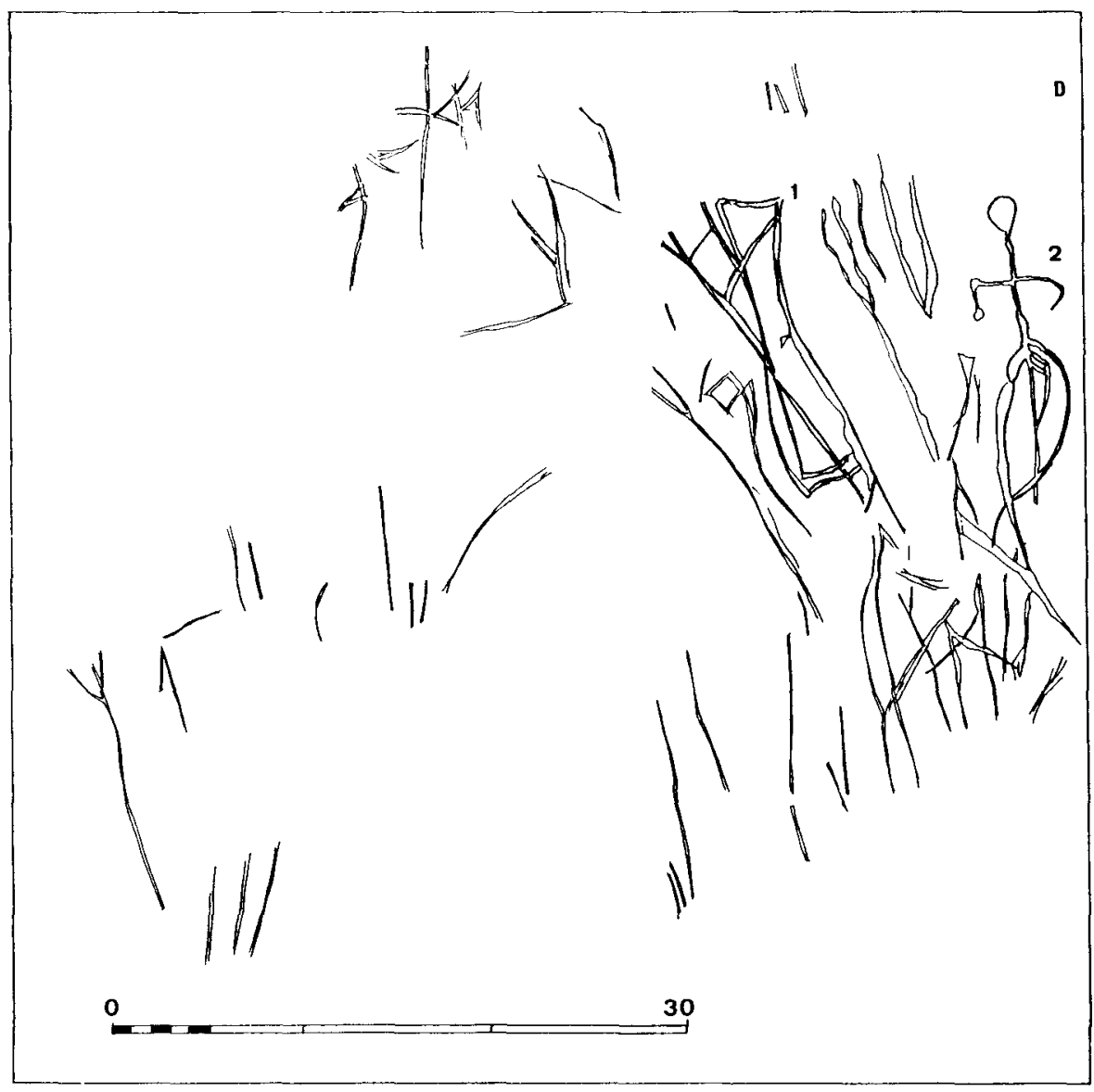

Fig. 7. Covarrubias: grabados de la zona $D$.

si bien entre aquellos aparece la figura animal (en Los Enebralejos, La Vaquera, San Garcia, Galeria del Silex, Kaite II, Chipichondo, Galeria de la Fuente, Sala de los Grabados y Goikolau) ausente de las cavernas sorianas. Entre las abstracciones son corrientes los zig-zags, reticulas, ángulos, heliomorfos o esteliformes y circuliformes, ramiformes, pectiniformes, rayados o haces de lineas y marañas, con particularidades individuales que pueden personalizar a cada una de las cuevas pero no disociarlas del ciclo.

Elemento importante y definitivo en el estudio y sistematización del ciclo será la constatación, en buena parte de ellas, de yacimiento arqueológico que bien pudiera contextualizar las manifestaciones artísticas. Entre las sorianas, el yacimiento arqueológico falta en San Bartolomé 


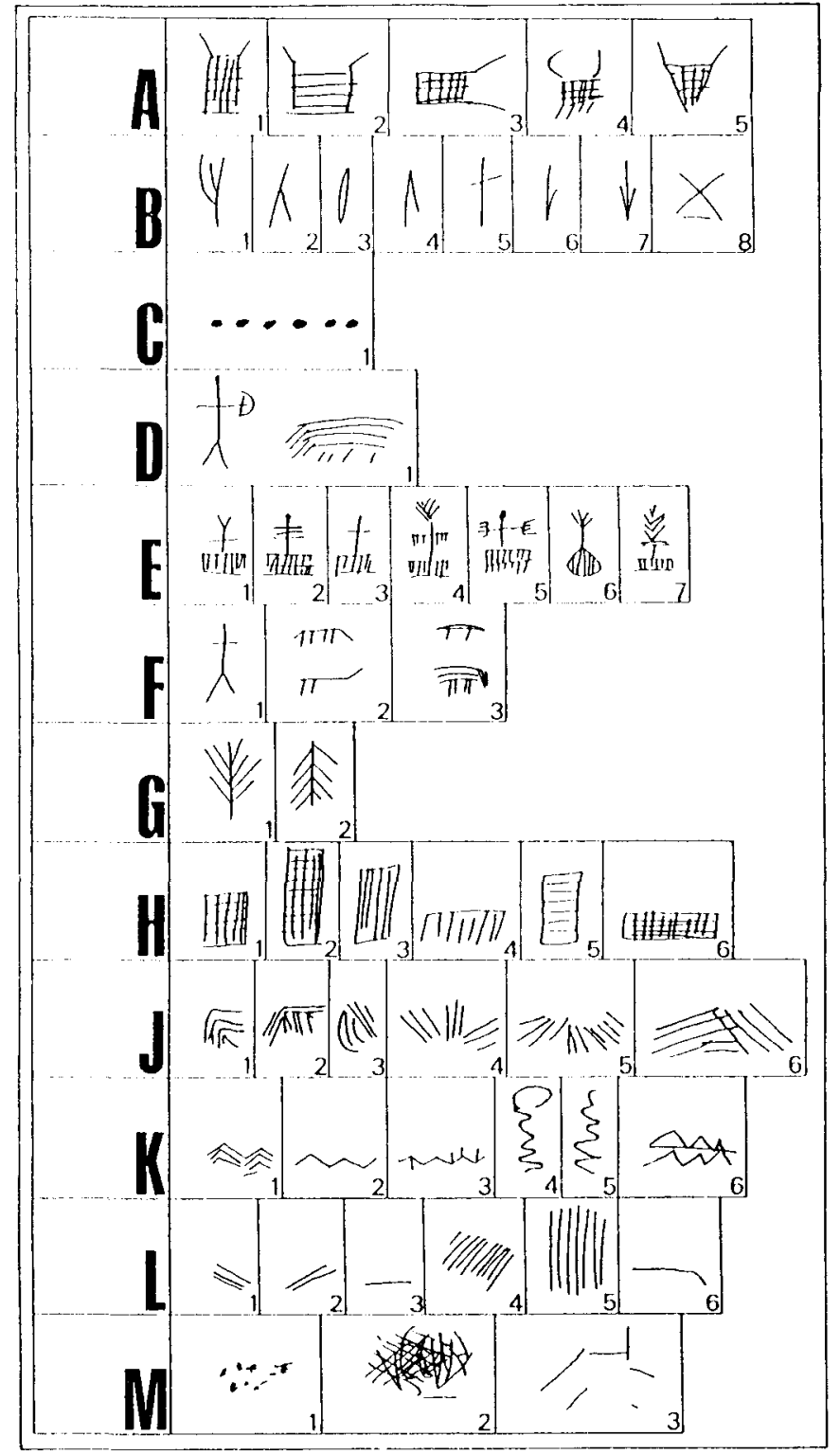

Fig. 8. Cuadro tipológico de la Galeria del Silex con agrupación de sus 12 familias según Apellániz y Uribarri (1976: 153-158, fig. 78-80); elaboración propia. 
Manifestaciones de la facies esquemática en el centro...

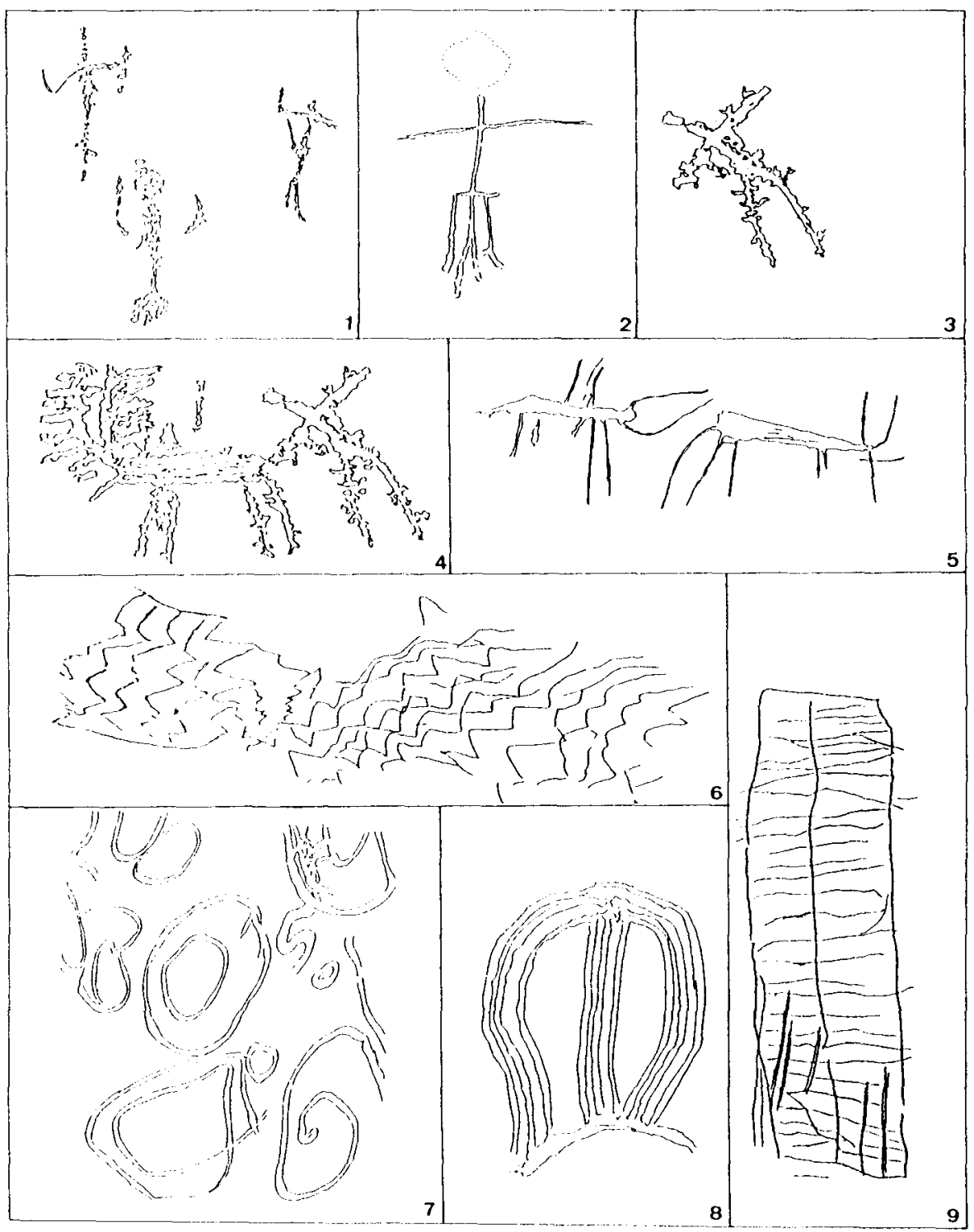

Fig. 9. Antropomorfos (1, 2 y 3) cuadrúpedos (4 y 5) y motivos en zig zag (6) de la Sala de la Fuente; grabados tipo "macarroni» de la galeria del mismo nombres (7); "cabaña" de Cueva Kubia (8) y tectiforme (9) de la Galeria de los Grabados. Dibujos del autor a partir de fotografia de M. A. Martín (Ortega y Martin 1986). 
- aunque el horizonte cultural de sus alrededores sitúan sus cuevas en la Edad del Bronce (Garcia-Soto Mateos y Moure Romanillo 1984: 159)y ha sido objeto de excavación en Covarrubias y Cueva Maja, denunciando la primera dos momentos diferentes de ocupación: tardorromano, el uno, y postcampaniforme, el otro, mientras que en Cueva Maja se ha constatado un único nivel cuyo material arqueológico corresponderia al Bronce Antiguo.

Aún a falta de excavaciones sistemáticas en gran parte de los yacimientos citados, la mayoría de las cuevas que compondrían la referida provincia artistica presentan un horizonte cultural relacionable, arqueológica y cronológicamente, con los yacimientos sorianos. Las cuevas segovianas de Los Enebralejos y La Vaquera han documentado sendas necrópolis calcoliticas de inhumación colectiva, evidencias de una intensa actividad cultual y una supuesta vinculación del arte rupestre de sus paredes y techumbres con la utilización de las cuevas como espacios sepulcrales (Municio y Zamora 1989: 274). Las burgalesas de San García, Galeria del Sílex, Penches y las cavernas y galerías del complejo kárstico de Ojo Guareña, pese al ya necesario e imprescindible estudio exhaustivo de estas últimas, muestran un importante conjunto artístico encajable en el ciclo analizado y con yacimiento arqueológico constatado en San Garcia y Galeria del Silex y denunciado, a través de hallazgos de superficie, en Kaite II, Chipichondo, Keimada y Kubia. Moure y Garcia-Soto (1986: 203) piensan que estos yacimientos decorados podrian atribuirse, en base a sus restos arqueológicos, a poblaciones de la fase Protocogotas y Cogotas I, no descartando un origen o precedente de sus grabados y pinturas en el Bronce Antiguo meseteño. Esta atribución cultural para el ciclo artístico descrito quedaría confirmada de alguna forma, y pese a la escasez de datos arqueológicos referidos a los yacimientos situados en la zona oriental cantábrica, por la fecha radiocarbónica de 1760100 a. C. obtenida A. Llanos de Solacueva (1989ep) y la asociación de las primeras manifestaciones artísticas esquemáticas alavesas a un ambiente de cerámicas lisas o decoradas con cordones plásticos. Las asociaciones directas entre las manifestaciones artísticas y las arqueológicas evidentes por los paneles de los Grupos H y J de Cueva Maja (Gomez-Barrera 1991) $y$ el fragmento de fondo cerámico con reticulado inciso en su pared exterior aparecido al pie de aquellos, los antropomorfos del panel XXV de la Galeria del Silex y la figuración del vaso C-12 obtenido, también, al pie de las muestras rupestres (APELLANIZ y Domingo 1987: 25) y el ídolo calizo con representación pectiniforme similar a otras de igual carácter grabadas en la Cueva de Los Enebralejos (Municio y PIÑON 1986-87: 139-140) han venido a confirmar las atribuciones arqueológicas y su relación con los grabados. 
Manifestaciones de la facies esquemática en el centro ...

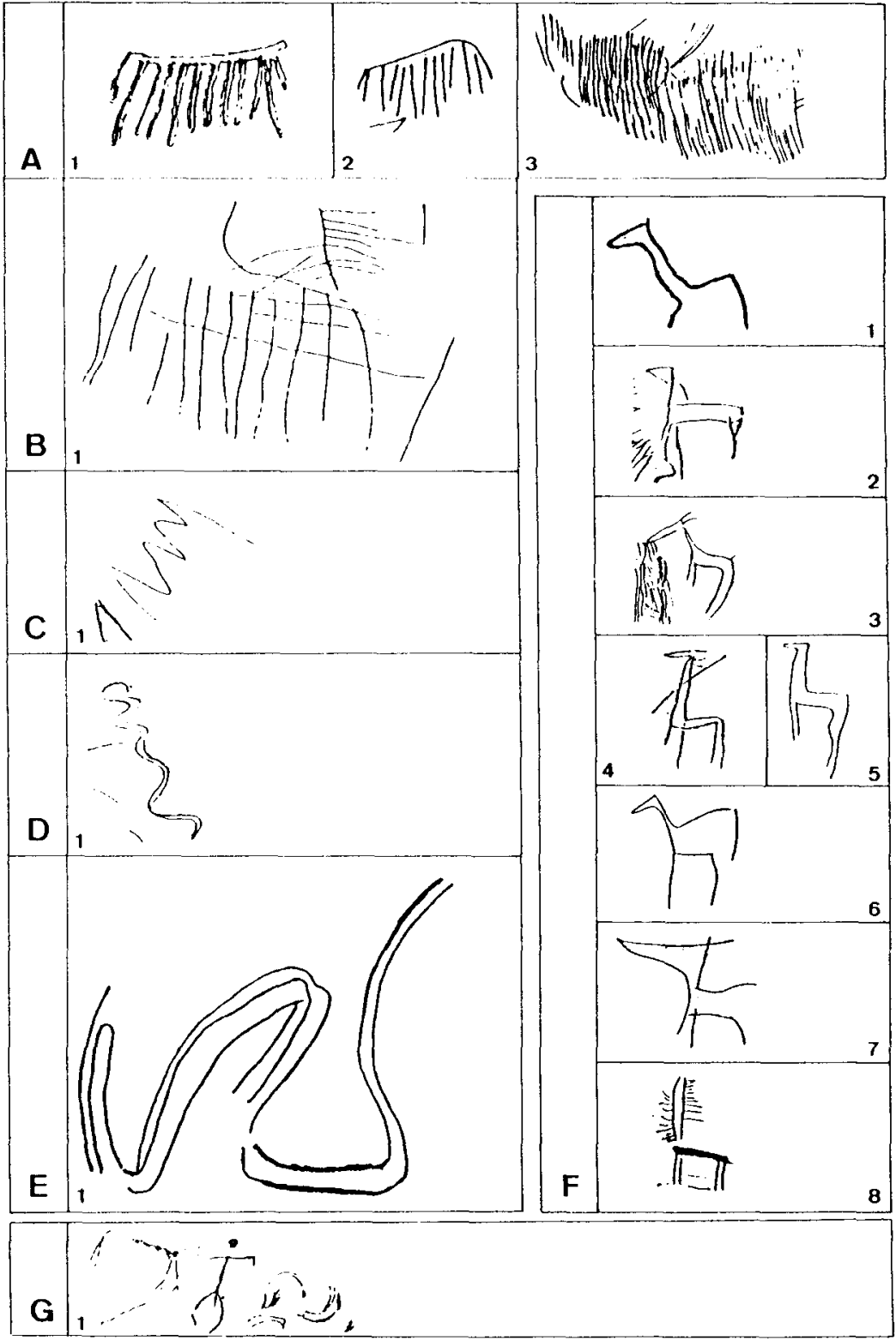

Fig. 10. Cuadro tipológico de Kaite II: A) Pectiniforme, B) Tectiformes, C) Zigzag, D) Serpentiformes, E) Meandros, F) Figura animal y G) Figura humana. Elaboración propia a partir de los calcos de Uribarri y Liz, 1973. 
En otro lugar (Gomez-BARRERA 1990b: 107; 1991: 486) hemos relatado como, al ocuparse de los grabados parietales de Cueva Mayor y Menor de San Bartolomé de Ucero, los profesores Garcia-Soto y Moure señalaban cómo el tipo de arte que éstas presentaban, peculiar y poco conocido, habia sido soslayado por los investigadores en favor de otras manifestaciones artísticas más actractivas o más fáciles de observar (1984: 159$160)$. Se referian ellos a unas muestras grabadas que $\sin$ embargo, amparadas por el propio brillo de estaciones como Atapuerca y Ojo Guareña, estaban siendo avaladas y reconociéndose, de manera clara, su carácter prehistórico. En efecto, la uniformidad artística y el convencimiento de que se tratase de conjuntos cerrados asociados al yacimiento material en ellas contenido, legitimaron cronologías e interés prehistórico de núcleos de arte rupestre tan notables como las cuevas burgalesas citadas, las segovianas de Torreiglesias, Prádena y Pedraza e, incluso, las sorianas de Ciria y Cabrejas del Pinar asi como todas aquellas enumeradas en el apartado anterior.

La cuestión se agrava, no obstante, cuando nos encontramos con yacimientos artisticos al aire libre, sin contexto arqueológico preciso, con evidentes muestras de modernidad en los grabados - ya sea por medio de grafitos o inscripciones medievales o modernas o a través de repasos contemporáneos - y donde la sacralización de ciertos lugares y su perduración en el tiempo ha podido determinar la continuidad en el grabado y su complejidad actual.

A nivel peninsular, el conjunto al aire libre más llamativo y principal es el que se desarrolla por las provincias gallegas, fundamentalmente en Pontevedra. Los constantes descubrimientos, catalogaciones y trabajos de sintesis ponen de manifiesto su interés cultural (Costas Goberna 1987; Pérez Paredes y Santos Estévez 1987) y su cronología - si bien en algunos elementos alcanza tiempos históricos - parece abarcaria desde periodos avanzados del megalitismo hasta la Edad del Hierro con un amplio desarrollo intermedio en la Edad del Bronce. Cazoletas, circulos, espirales, laberintos, cuadrados, zig-zags, etc., conformarian una amplia temática geométrica que se intercalaría con otros temas seminaturalistas con representaciones de cuadrúpedos - caballos y cérvidos-, figuraciones humanas y alabardas, puñales, cascos, paletas e idolos (PEÑA SANTOS y Vazouez Varela 1979; Garcia Alén y Peña Santos 1980).

Se ha querido ver una expansión de los grabados gallegos hacia el Este, Sur y Suroeste citándose al idolo de Peña Tú de Vidiago y los grabados del pico del Burru, en Asturias; las estaciones portuguesas y ex- 
Manifestaciones de la facies esquemática en el centro ...

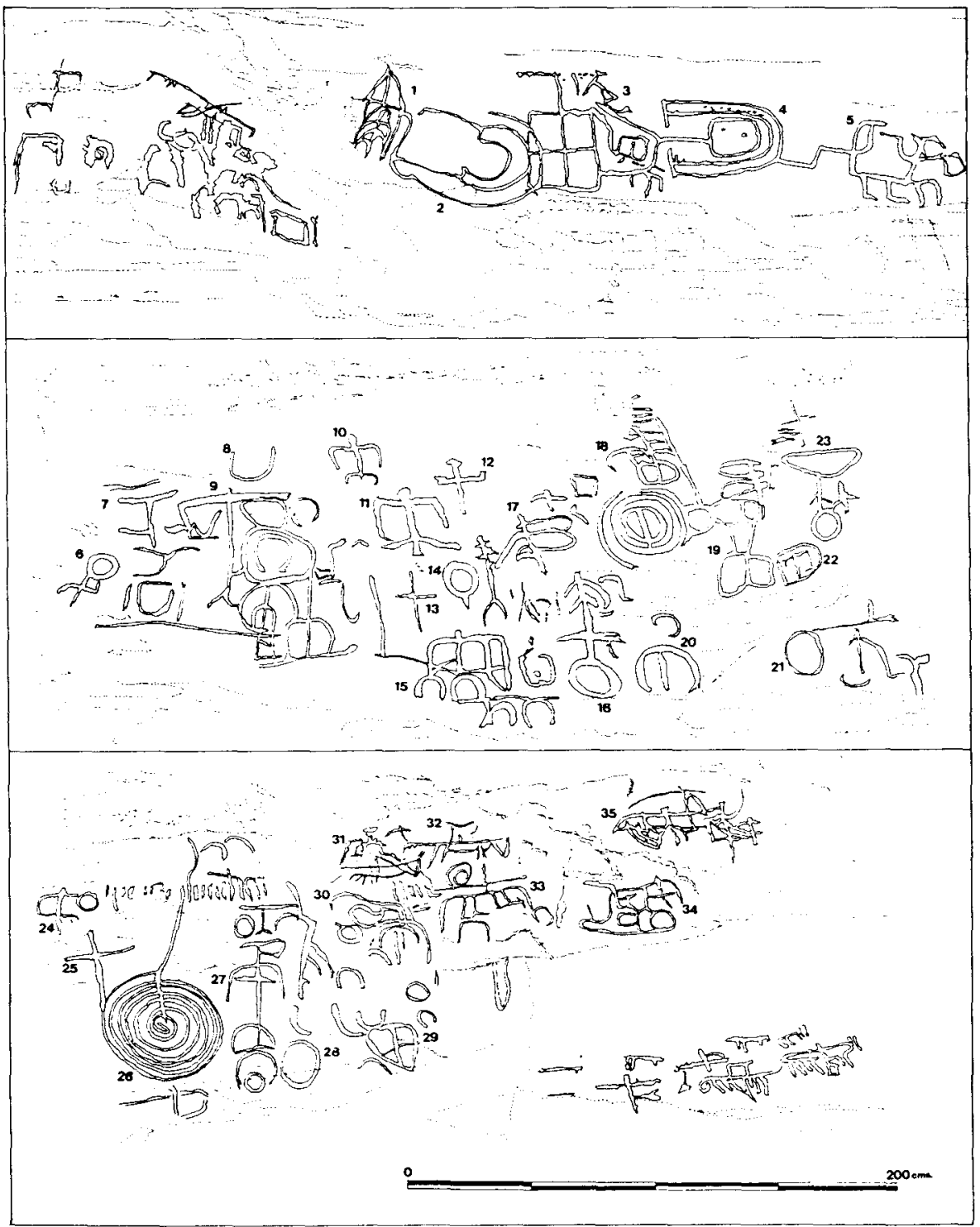

Fig. 11. Detalles del panel del Abrigo III. D del Barranco de la Mata (Soria).

tremeñas; la Laja de los Hierros en Cádiz; el grupo de grabados de Tahal (Almeria) y las cazoletas del Monte Arabi de Yecla, en el sureste; el grupo de Domingo Garcia y Santa Maria de Nieva, en Segovia; la roca de las 
Ferraduras de Capafons, en Tarragona; o las muestras sorianas hasta entonces conocidas (NIETO 1985: 493-499).

La lista podria ampliarse con descubrimientos más recientes en la provincias de Lérida, Jaén, Barcelona, Teruel, Navarra, Zaragoza, etc.

La valoración cultural y cronológica de estos grabados -excepción hecha de los gallegos y portugueses - ofrecen, en el momento actual de investigación, muchas dudas y plantea grandes problemas, Jordá, en alusión directa a las insculturas galaico-portuguesas, puso de manifiesto cómo éstas tienden a desaparecer en la zona que les es propia al tiempo que en áreas periféricas a la misma surgen representaciones rupestres grabadas que las recuerdan y que en cierto modo responderian a su difusión (JORDÁ, 1978: 148). Ripoll, aparte de catalogar estos grabados como representaciones de un arte de época imprecisa entre la Edad del Bronce y la Protohistoria (1981: 148), ha dejado constancia de la necesidad de poner en relación los petroglifos existentes en diferentes lugares de la Peninsula con las insculturas del noroeste gallego (1968: 190). Y Acosta, por su parte, habla de una gran variabilidad temática y de una hipotética clasificación en tres grupos según se acerquen o alejen de la temática de la pintura esquemática, de los grabados galaico-portugueses o de ambos, estableciendo una cronologia amplia que no solamente ocuparia el primer milenio a. C. sino que se prolongaria hasta la época histórica. Crítico con el carácter prehistórico de estas manifestaciones se nos muestra Beltrán, quien piensa que es posible nos hallemos ante manifestaciones intemporales de tipo infantil o simplemente inhábil que no duda en llevar a la Edad Media (1989: 43).

Es evidente que la problemática general de estos grabados pasa por la confección de estudios parciales, detallados y pormenorizados de todas las zonas con la pretensión de conformar, después, una sintesis al modo y manera como se hizo con la pintura esquemática. En este sentido es digno de mención el trabajo de Sevillano San José llevado a cabo sobre los grabados rupestres de la comarca de Las Hurdes (1985) o el de Martín Valls sobre las insculturas del castro de Yecla de Yeltes (1983: 217-231).

En nuestra Tesis Doctoral (Grabados rupestres postpaleoliticos del Alto Duero) además de inventariar, sistematizar y relacionar las manifestaciones sorianas, quisimos avanzar en la elaboración de una primera sintesis de los grabados al aire libre recogiendo todas sus muestras hasta ahora conocidas. Para ello se tuvo muy presente que la diferenciación técnica, temática, cultural y cronológica de los mismos -cuyo tronco común queda en muchos casos reducido a su carácter de grabado al aire libre- podría llevarnos a la confección artificial de un amplio "cajón de sastre" - en otro lugar denunciado - en el que se mezclen las tendencias 
Manifestaciones de la facies esquemática en el centro ...

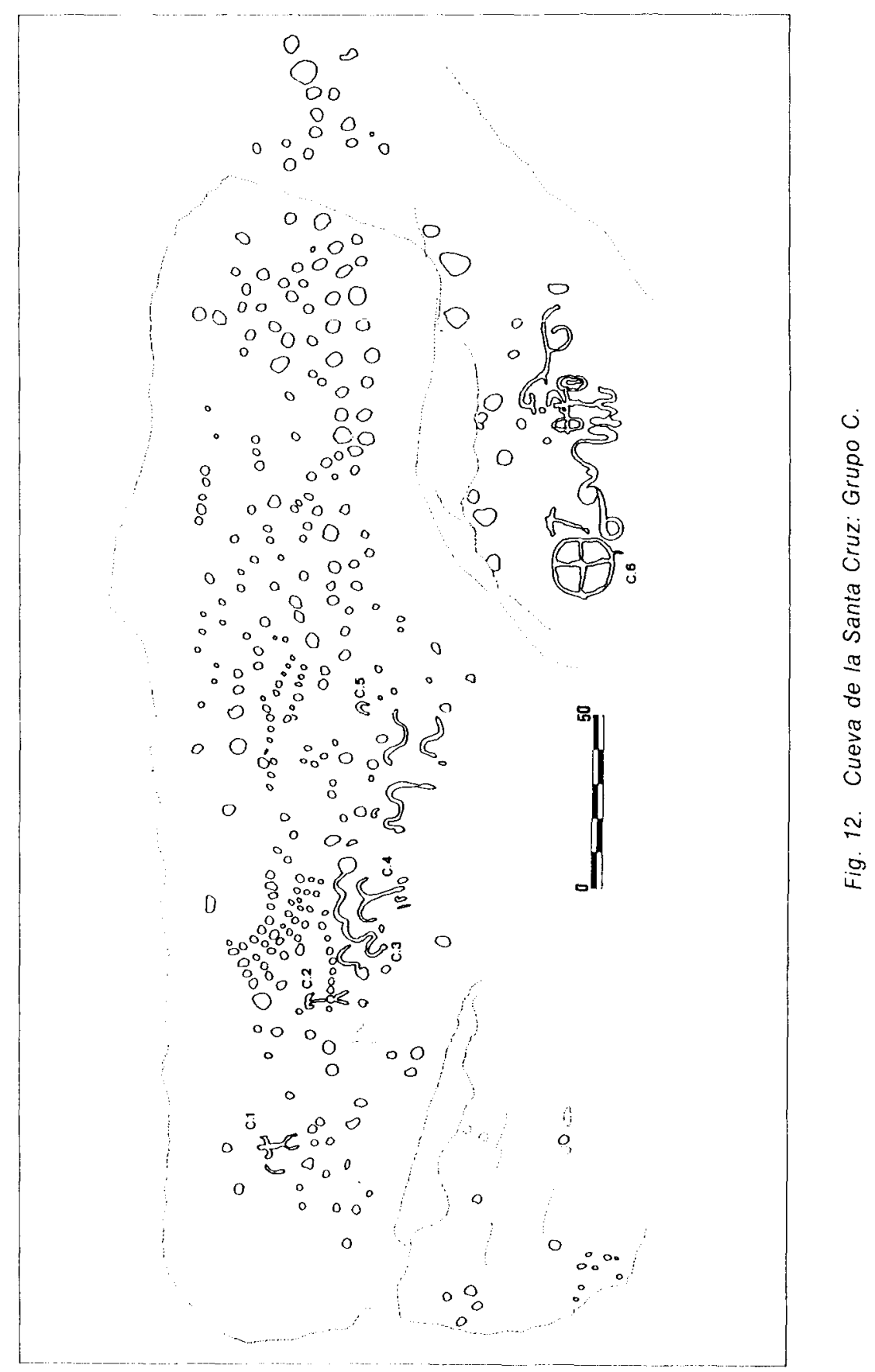


y nos embarcase en una confusión mayor. Con la idea de no caer en este error, la relación de estos núcleos de arte rupestre se hizo aplicando un criterio de agrupación zonal por cuencas fluviales, tal y como recomendara Bécares (1983: 137-148), a la vez que se huía de aproximaciones tipológicas y caracterizaciones generales que pudieran alterar el mantenimiento de sus múltiples aspectos diferenciales.

No es este el lugar donde presentar el inventario elaborado por lo que, tras recordar por simple enumeración los grabados al aire libre conocidos en la Meseta Norte (Covacho del Molino Giriego, Domingo Garcia y comarca de Santa María de Nieva, en Segovia; Sierra del Guadarrama, entre Segovia y Ávila; Muñogalindo, en la Sierra de Ávila; El Pedroso, en Zamora; Yecla de Yeltes, en Salamanca y los sorianos de la Cueva de la Santa Cruz. Barranco de la Mata, Tiermes-Sotillos, Valle del Rio Manzanares, Valvenedizo-Castro, Cañada del Monte, Cuento del Cerro y Cueva Grande), pasaremos a comunicar algunas características del grupo soriano y aquellas otras que puedan ser admitidas ya a nivel peninsular.

Los grabados al aire libre sorianos se localizan - con la excepción de Cueva Grande, hallazgos sueltos de la cabecera del Duero y Cueva de La Santa Cruz - en covachos y abrigos situados en lugares destacados, de amplia visibilidad desde los mismos y formando parte de grandes cuerdas rocosas que recorren, en orientación W-SW, amplios espacios limitando barrancos, valles o cañadas en áreas de parameras, zonas arrasadas y marginales, con caracteristicas de comarca de montaña muy apropiadas para el pastoreo. En su mayoria aparecen en estaciones próximas a diferentes cursos de agua y otras se enclavan en lugares de paso entre montañas. $Y$, en general, ofrecen una temática variada, susceptible de ser concentrada en dos grandes grupos según representen figuraciones, más o menos relacionables con un modelo real cognoscible, o composiciones abstractas, lineales o geométricas, que determinarian quince tipos (antropomorfos, cuadrúpedos, jinetes, circuliformes, petroglifoides, idolos, barras, puntos, cazoletas, zig-zags, serpentiformes, herraduras, tectiformes, esteliformes y restos lineales), una constante repetitiva expresada en la presencia masiva del motivo en herradura, de las cazoletas y de la figura humana y animal — con cierto diseño naturalista y abundancia del jineteen todos los núcleos y la escasez de motivos idolos, petroglifoides, espiraliformes y esteliformes.

Del análisis técnico de los distintos motivos se infiere el uso de un grabado en surco, resultante de la aplicación de técnicas de repiqueteado -en su gran mayoría- e incisiones sobre las que actúan, en menor medida, otras abrasivas. No son pocos los ejemplos en los que se contemplan repasos posteriores que, asi como afirman la pervivencia de cierta 


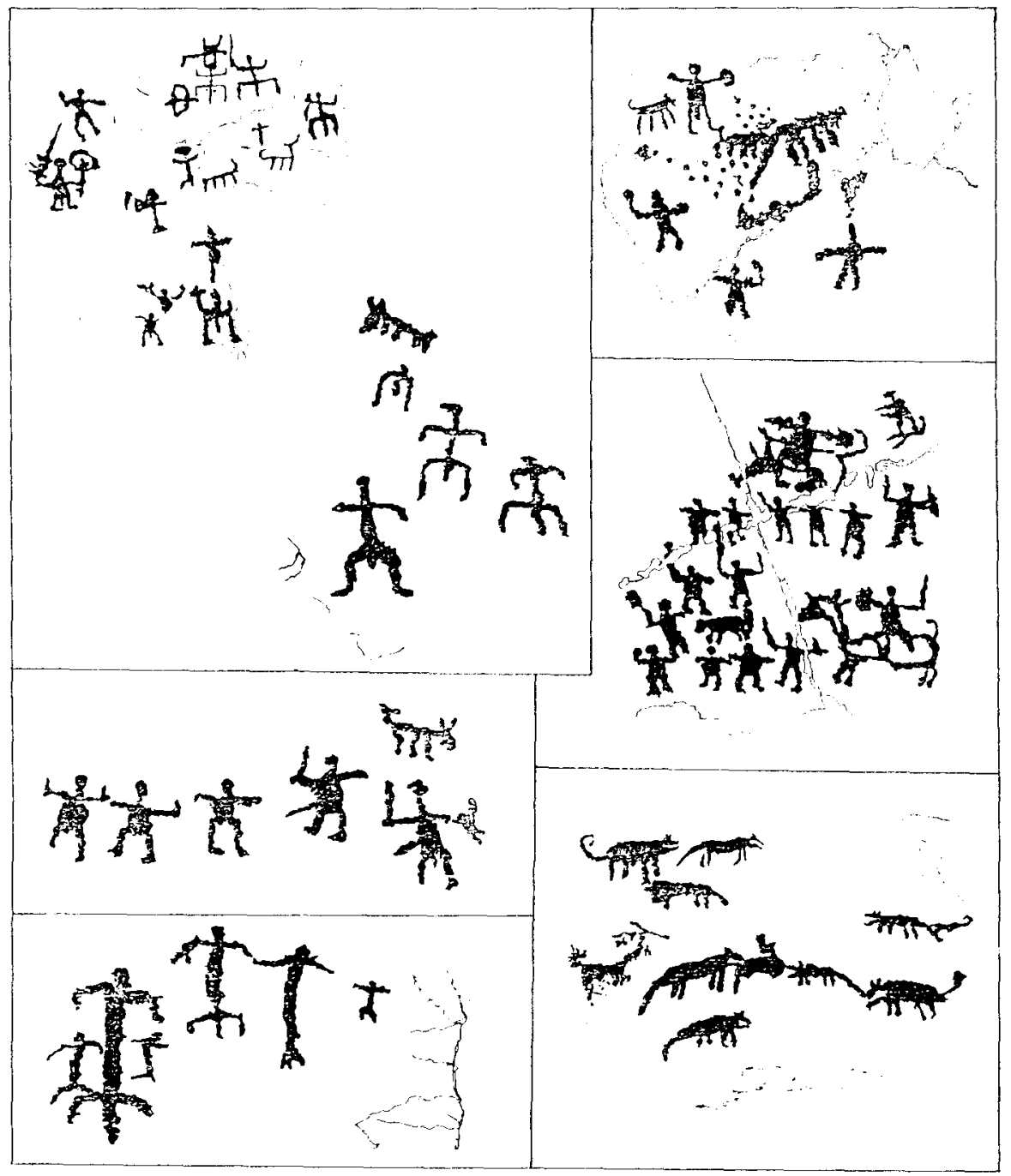

Fig. 13. Grabados de la Sierra de Guadarrama (E. Álvaro Bobadilla).

inquietud (¿artistica?, ¿religiosa?) y utilización tradicional del lugar (Conquezuela), han ocasionado alteraciones y pérdidas del motivo original.

No se da en la provincia de Soria ningún yacimiento arqueológico definido que pueda ponerse en relación directa con alguno de los núcleos de grabados al aire libre. Las referencias arqueológicas con las que se han venido asociando a los grabados se apoyan en hallazgos sueltos, mal 
definidos y peor localizados, dudosamente relacionables con las manifestaciones artísticas aunque, eso si, señalarian un horizonte cultural para la zona de raíces calcolíticas, amplio desarrollo hasta el Bronce Medio con asentamientos dispersos y alineados a lo largo del piedemonte del Sistema Central, prolongación en la Edad del Hierro y romanización y pervivencia hasta la Edad Media. Todo ello estaria en base a un dominio económico ganadero-pastoril que nos inclinan a pensar, tras los análisis descriptivos, tipológicos y técnicos, que los grabados del suroeste soriano fueron obra de una comunidad marginal y retardataria (de amplia prolongación en el tiempo) y economia tradicional de tipo pastoril.

Del inventario-resumen a nivel general de las estaciones grabadas al aire libre hasta ahora conocidas se desprende, dejando al margen el ciclo galaico-portugués, la dispersión de estas manifestaciones por las estribaciones y piedemonte de las grandes unidades del relieve peninsular,

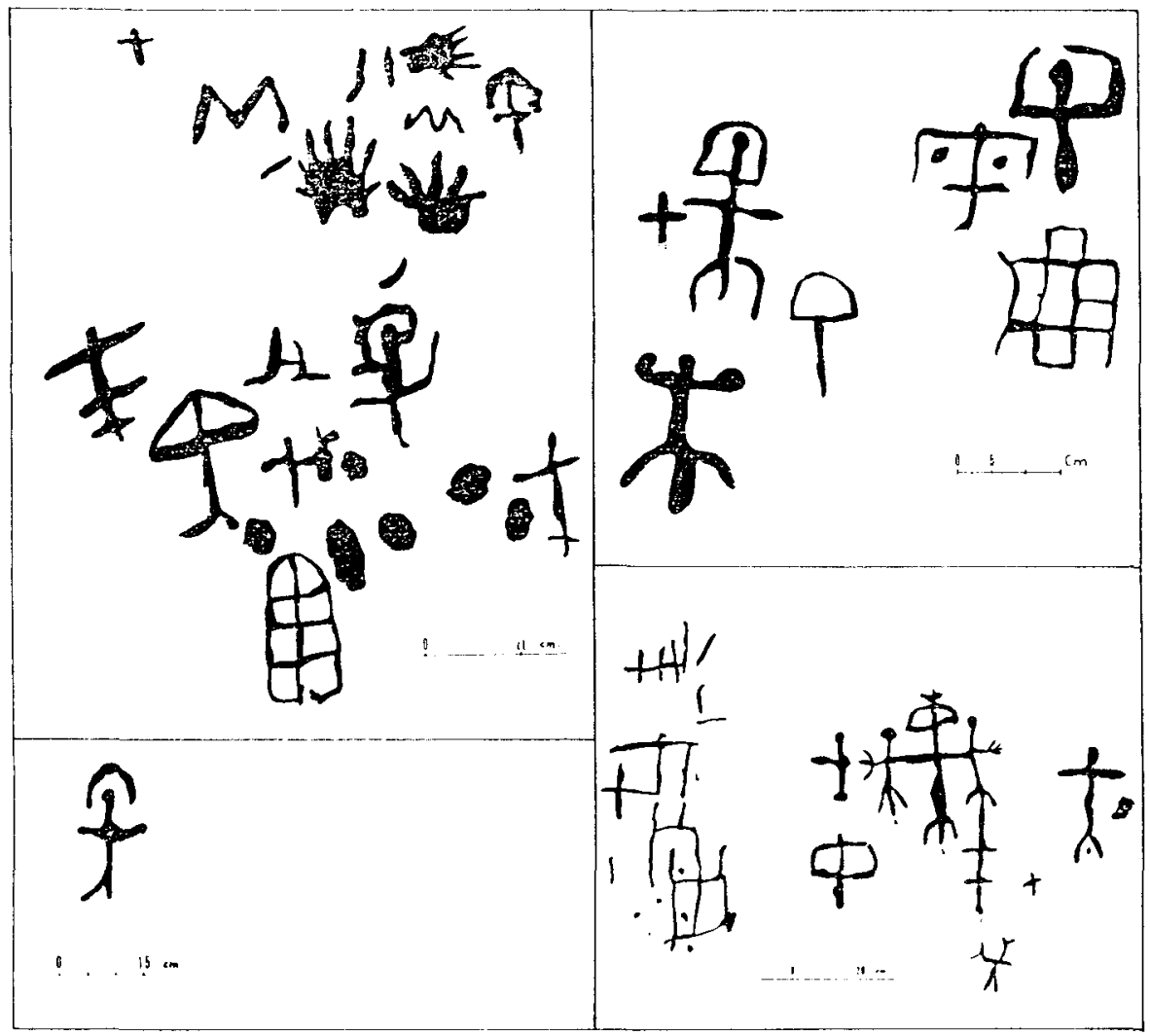

Fig. 14. Grabados del Castro zamorano del Pedroso (Esparza Arroyo). 
en una localización paralela aunque no coincidente con la pintura esquemática. La utilización de abrigos y covachos como soportes de los grabados, el generalizado uso de técnicas de repiqueteado o picado y la repetición tipológica, dentro de una gran variedad regional, de motivos antropomórficos, cruciformes, herraduras, cazoletas y abstracciones geométricas, son afinidades comunes en el conjunto de los grabados al aire libre de la Península Ibérica. Arqueológicamente sólo los grabados de El Pedroso (Esparza 1977) y Yecla de Yeltes (Martin Valls 1973 y 1983) aparecen claramente relacionados con yacimientos materiales mientras que al resto de los grupos se les ha venido asociando a un horizonte cultural Calcolitico y Edad del Bronce en general en razón de su proximidad o comparación de alguno de sus motivos con diversos hallazgos semejantes en apreciación cronológica (GaRCIA SANCHEZ y SPAHNI 1958; Amo 1974; Atrian Jordán 1980; Benavente Serrano 1986-87). No se descarta, tampoco, una larga pervivencia que llevaría a muchos de ellos a una datación en la Edad del Hierro, romanización y Edad Media (Álvarez y Cebolla 1985; Diez Coronel 1986-87; Cerdeño y Garcia 1983). Si parece claro, por contra, su ambientación en un sistema económico basado en el pastoreo y en una agricultura marginal (BLAS CORTINA 1974).

A gran parte de estas muestras plásticas se les ha venido situando en un mundo dolménico ante la presencia de insculturas -o pinturas - de igual tono en alguno de sus ortostatos, circunstancia ésta utilizada para establecer el momento más antiguo del fenómeno esquemático grabado (López Plaza 1983; Giménez Reina 1956; Delibes y Rojo 1989). Es la misma relación que se ha querido ver con la pintura esquemática, acentuada por la general aparición de las pictografias en abrigos y covachos al aire libre, la coincidencia repetitiva de alguno de sus motivos y un horizonte cultural basado en evidencias arqueológicas tan precarias como las que acompañan a los grabados. Justamente la escasa asociación en un mismo motivo o panel de pintura y grabado y la distribución próxima pero no coincidente de sus estaciones, hizo pensar a Fortea (1970-71) que el origen de estos grabados estaria en los momentos finales de la pintura considerándole un «eco» tardio de la misma.

\section{A MODO DE CONCLUSIÓN Y FINAL}

Tras esta aproximación al estudio de las manifestaciones rupestres del centro y norte de la Peninsula bien podemos decir, a modo de conclusión, que la diferenciación entre la pintura esquemática y el grabado no sólo se manifiesta en las diversas técnicas usadas en sus trazados y 
en la distinta distribución zonal de sus yacimientos si no, también, en una serie de particularidades relacionadas con la temática y su reiteración, aspectos, por lo demás, tenidos siempre como definitivos en sus asociaciones. Los tres ciclos artísticos reconocidos en territorio soriano $-y$ en el territorio que abarca esta lección- han sido sometidos a un análisis tipológico comparado a través del cual han quedado en evidencia los escasos contactos existentes entre grabados al aire libre y grabados en cuevas, se ha determinado una coincidencia notable entre estos últimos y la pintura esquemática — si bien limitada a la reducida variedad temática de las cavidades - y, finalmente, se ha confirmado una más amplia y aparente semejanza entre la pintura y los grabados al aire libre que repiten, en múltiples variantes, los tipos pictóricos esquemáticos a la vez que se desligan de su tradición con la presencia de motivos extremos (figuras humanas realistas, cruciformes, jinetes y elementos geometrizantes) de larga pervivencia.

Con todo, y como mera hipótesis de trabajo deducible de las investigaciones realizadas en nuestra Tesis Doctoral, proponemos como cronologia base del estudio del arte rupestre postpaleolitico del Alto Duero - y de alguna manera y con sus propias particularidades de la Meseta Norte española - una secuencia evolutiva que arrancaría en el Calcolítico con el inicio de las formas esquemáticas pintadas y grabadas en cuevas; se prolongaría con un amplio desarrollo de éstas a lo largo del Bronce Antiguo para, a partir del Bronce Medio, y como consecuencia del descenso poblacional denunciado por la escasez de yacimientos correspondientes a este período (JIMENO y FERNÁNDEZ 1989ep), producirse un debilitamiento artístico que, sin embargo, no impediria la pervivencia de la tradición esquemática a lo largo del Bronce Final y Primera Edad del Hierro con la incorporación de motivos nuevos (por ej.: "trisceles" del Covachón del Puntal y motivo-estela de La Peña los Plantios). El recuerdo de la vieja práctica pictórica conllevaria, en poblaciones marginales de economía pastoril, la aparición, ya desde el Bronce Medio, del grabado al aire libre que, en diseños más toscos y rudos en clara consonancia con las posibilidades técnicas de sus autores, veremos prolongarse por la Edad del Hierro, romanización y Edad Media con reducidos, aunque significativos, cambios en su temática.

Concluir algo en arqueologia prehistórica es prácticamente imposible. Hipotizar es no solamente posible sino necesario. Concretar las facies esquemáticas del Alto Duero, y por extensión su región circundante, ha sido -y seguirá siendo- mi tarea de investigación de la que aquí les he intentado mostrar mis escasos logros, pocos, si, y discutibles, también, pero rebosantes de humildad cientifica. 


\section{BIBLIOGRAFIA}

Acosta, P. (1968): La pintura rupestre esquemática en España, Salamanca.

- (1984): “El arte rupestre esquemático ibérico: problemas de cronologia preliminares", Scripta Praehistorica. Francisco Jordá. Oblata, Salamanca. págs. 31-61.

- (1986): "Arte rupestre postpaleolitico hispano", en (F. Jordá Cerdá et alii), Historia de España. 1. Prehistoria. Madrid, Ed. Gredos, págs. 265-299.

Alvaro Bobadllla, E. (1989): "Nuevos grupos de arte rupestre en la Meseta Norte», XIX Congreso Nacional de Arqueologia (Castellón 1987). Zaragoza, págs. 471-477

Alvarez Garcia, A. y Cebolla Berlanga, J. L. (1985): "Los grabados rupestres de Las Peñetas. Nonaspe (Zaragoza)", Cuadernos de Estudios Caspolinos, Xl, págs. 157-166.

Amo, M. del (1974): «Los grabados rupestres de Los Aulagares (Zalamea la Real, Huelva)", Miscelánea Ampuritana. XXV Aniversario de los Cursos de Ampurias (1947-1971), vol. I págs. 69-86.

Apellaniz, J. M. y Domingo Mena, S. (1987): “Estudios sobre Atapuerca (Burgos). II. Los materiales de superficie del Santurario de la Galería del Sílex», Cuadernos de Arqueologia de Deusto, 10. Bilbao.

Apellaniz, J. M. y URibarRI, J. L. (1976): «Estudios sobre Atapuerca (Burgos). I. El Santuario de la Galería del Sílex", Cuadernos de Arqueologia de Deusto, 5, Bilbao.

Atrian JoRdan, P. (1980): "Los grabados rupestres del Barranco Cardoso, Almohaja (Teruel)», Rev. Teruel, 64, págs. 113-125.

Balbin Behrmann, R. de (1989): “El arte megalitico y esquemático del Cantábrico», en (M. R González Morales, ed.) Cien Años Después de Sautuola. Santander, págs. 15-96.

Baldellou, V. (1989): “ll Reunión de Prehistoria Aragonesa: La terminología en el arte rupestre post-paleolitico», Bolskan, 6, págs. 5-14.

Becares Pérez, J. (1974): “Nuevas pinturas rupestres en Las Batuecas: El Covacho del Pallón», Zephyrus, XXV, págs. 281-294.

- (1976): "Pinturas del Corral de Morcilla (Las Batuecas)", Zephyrus, XXVI-XXVII, págs. 225-232.

- (1983): “Hacia nuevas técnicas de trabajo en el estudio de la pintura rupestre esquemática", Zephyrus, XXXVI, págs. 137-148.

- (1987): "Arte rupestre prehistórico en la Meseta", en Arte Rupestre en España, Revista de Arqueologia, pág. 86-95.

- (1991): "La pintura rupestre esquemática en la provincia de Salamanca", Del Paleolitico a la Historia. Museo de Salamanca, págs. 61-79.

Becares Pérez, J.; Rivero de la Higuera, C.; Gómez Fuentes, A. y Civieta Rojas, C. (1980): «Pinturas rupestres esquemáticas del Bonete del Cura (Ciudad Rodrigo. Salamanca) $\%$. Zephyrus, $X X X-X X X \mid$, págs. 131-146.

Beltran Martinez, A. (1989a): Ensayo sobre el origen y significación del arte prehistórico. Zaragoza, Prensas Universitarias.

- (1989b): El arte rupestre aragonés. Aportaciones de las pinturas prehistóricas de Albalate del Arzobispo y Estadilla. Zaragoza. IberCaja.

- (1989c): Los parques culturales y el arte rupestre en Aragón. Zaragoza, Diputación General de Aragón.

Benaventa Serrano. J. A. (1986-87): "Los grabados rupestres de La Coscollosa (Alcañiz, Teruel)", Bajo Aragón. Prehistoria, VII-VIII, págs. 107-118.

Blanco, R. (1986): «Avance al estudio de las pinturas rupestres esquemáticas de la Cuenca Alta del Ebro", Mesetaria 2, Burgos, págs. 59-96.

Blas Cortina, M. A. (1974): "Los grabados rupestres del Picu Berrubia», Ampurias, 36, págs 63-86.

Breull, H. (1918-19): "Les peintures rupestres de la Péninsula Ibérique. IX. La vallé peinte des Batuecas (Salamanca). X. Roches peintes de Garcibuey (Salamanca)", L'Anthropologie, XXIX. págs. 1-27. 
- (1933-35): Les peintures rupestres schématiques de la Péninsule lbérique. Lagny (4 vols.).

Breull, H. y Obermaier, H. (1913): "Institut de Paleontologie Humaine, travaux executees en 1912", L'Anthropologie XXIV, págs. 1-16.

CABRE, J. (1922): “El hombre prehistórico de Las Hurdes. (Las pinturas rupestres de Las Batuecas)", Coleccionismo, 116. Madrid, págs. 142-160.

- (1941): “Pinturas y grabados rupestres, esquemáticos, de las provincias de Segovia y Soria", Archivo Español de Arqueologia, XLIII, págs. 316-344.

Carrasco, J.; Toro, I.; Medina, J.; Carrasco, E.; Pachon, J. A. y Castañeda, P. (1982): “Las pinturas rupestres del Cerro del Piorno (Pinos Puente, Granada). Consideraciones sobre el Arte Rupestre Esquemático en las Sierras Subbéticas andaluzas", Cuadernos de Prehistoria de la Universidad de Granada, 7, págs. 113-169.

Carrasco Rus, J.; Carrasco Rus, E.; Medina Casado, J. M. y Torrecillas Gonzalez, J. F. (1985): El fenómeno rupestres esquemático en la Cuenca Alta del Guadalquivir. I. Las Sierras Subbéticas, Prehistoria Gienense, 1. Granada.

Carrasco Rus, J. y Pastor MuNoz, M. (1983): "Aproximación al fenómeno esquemático en la cuenca alta del Guadalquivir", Zephyrus, XXXVI, págs. 167-177

Cerdeno, M. ${ }^{a}$ L. y Garcia Huerta, R. (1983): "Noticia preliminar de los grabados de la Peña Escrita (Canales de Molina, Guadalajara)", Zephyrus, XXXVI, págs. 179-186.

Costas Goberna, F. J. (1987): «El petroglifo del Monte Tetón en Tebra (Tomiño). Grupo 1. Petroglifos: levantamiento de calcos y fotografia», Castrelos, 1/2, págs. 27-49.

Deliees de Castro, G. y Rojo Guerra, M. (1989): «Pintura esquemática en el sepulcro de corredor burgalés de El Moreco, Huidobro", Arqueologia, 20, G.E.A.P., Porto, págs. 49-55.

Diez-Coronel, L. (1986-87): “Grabados rupestres prehistóricos en el Pirineo Leridano y Andorrano del tipo "Roca de les Bruixes I", Bajo Aragón. Prehistoria. VII-VIII, págs. 235264.

Esparza Arroyo, A. (1977): "El castro zamorano del Pedroso y sus insculturas", BSAA, XLIII, págs. 27-39.

Fernandez Rivera, B. (1987): “Aproximación al estudio de las pinturas rupestres esquemáticas del Abrigo de El Castillón, Santa Eulalia de Tabara (Zamora)". Stvdia Zamorensia. Histórica, VIII. págs. 29-37.

FORTEA, J. (1970-71): "Grabados rupestres esquemáticos en la provincia de Jaén», Zephyrus, XXI-XXII, págs. 139-156.

Garcia Alen, A. y PeÑa Santos, A. de la (1980): Grabados rupestres de la provincia de Pontevedra. La Coruña.

Garcia-Soto Mateos, E. y Moure Romanillo, A. (1984): «Los grabados esquemáticos de San Bartolomé de Ucero (Soria)", I Symposium de Arqueologia Soriana, págs. 151-162

- (1987): “El arte rupestre de la cueva de San Garcia (Santo Domingo de Silos, Burgos) y otras manifestaciones perietales esquemáticas de la Submeseta Norte", XVIII Congreso Nacional de Arqueologia (Canarias, 1985). Zaragoza, págs. 513-523.

Garcia Sánchez, M. y SpahnI, J. C. (1985): "Grabados rupestres esquemáticos de época eneolitica, en Baños de Alicún (Granada)", Archivo de Prehistoria Levantina, VII, pázs. 121133.

Gimenez Rerna, S. (1956): "Los grabados rupestres del Arquillo de los Porqueros (Antequera, Málaga)», en Libro Homenaje al Conde de la Vega del Sella. Oviedo, págs. 207-219.

Gomez-Barrera, J. A. (1982): La pintura rupestre esquemática en la Altimeseta Soriana. Soria.

- (1984-85): «El Abrigo de La Peña los Plantíos: nuevo hallazgo de pinturas rupestres esquemáticas en Fuentetoba (Soria)", Ars Praehistórica t. IV-V. págs. 139-180.

- (1990a): "Pintura rupestre esquemática en Soria, significado e interpretación", Arte Prehistórico de la Provincia de Soria. Museo Numantıno, págs. 59-78.

- (1990b): "Grabados rupestres postpaleoliticos en la provincia de Soria", Arte Prehistórico de la Provincia de Soria, Museo Numantino, págs. 95-112. 
-- (1991): Grabados rupestres postpaleoliticos en el Alto Duero. Tesis Doctoral (inédita): UNED. Madrid.

Gonzalez-TABlas Sastre, F. J. (1980): "Las pinturas rupestres de Peña Mingubela (Avila): Zephyrus, XXX-XXX1, págs. 43-62.

Grande del Brio, R. (1987): La pintura rupestre esquemática en el centro-oeste de España (Salamanca y Zamora). Salamanca.

Grande del Brio, R., y Gonzalez-Tablas Sastre, F. J. (1982): "Las pinturas rupestres de las Peñas del Gato", Zephyrus, XXXIV-XXXV, págs. 141-144.

Guttérrez Gonzalez, J. M., y Avello Álvarez, J. L. (1986): Las pinturas rupestres esquemáticas de Sésamo, Vega de Espinareda (León): Centro de Investigación y Museo de Altamira, Monografías núm. 12, Madrid.

Hernandez Pacheco, E. (1922): “Dos nuevas localidades con pinturas en Las Batuecas (Salamanca)", Actas y Memorias de la Sociedad Española de Antropologia, Etnografia y Prehistoria, I. Madrid, págs. 185-206.

Jimeno Martinez, A., y Fernández Moreno, J. J. (1989ep): “El poblamiento desde el Neolitico a la Edad del Bronce: constantes y cambios", II Symposium de Arqueologia Soriana

JoRdA CERDA, F. (1970-71): "Los tocados de plumas en el Arte Rupestre Levantino", Zephyrus, XXI-XXII, págs. 35-72.

- (1978): "El arte de los pueblos agricultores, ganaderos y metalúrgicos, en (Jordá Cerdá, F., y Blázquez, J. M.) Historia del Arte Hispánico. 1, 1: La Antigüedad. Madrid, Ed. Alhambra, pág. 144-148.

Lopez Payer, M. G., y Soria Lerma, M. (1988): El arte rupestre en Sierra Morena Oriental (Jaèn, España). La Carolina, Jaén.

López PlazA, S. (1983): "Grabados rupestres esquemáticos en Muñogalindo (Ávila)», Zephyrus, XXXI, págs. 203-207.

Lucas PEllicer, M. ${ }^{a}$. R. (1971): “Pinturas rupestres del Solapo del Águila (Río Duratón, Segovia)". Trabajos de Prehistoria, 28, págs. 119-152.

- (1974): El arte rupestre de la provincia de Segovia, Cuadernos de Prehistoria y Arqueologia de la Universidad Autónoma, vol. 1, págs. 57-69.

- (1977): "La pintura rupestre esquemática del Barranco del Duratón (Segovia)", Resúmenes de Tesis Doctorales, Madrid, Universidad Autónoma, pág. 41-53.

- (1981): "Aproximación al conocimiento de las estaciones rupestres y de la pintura esquemática en el Barranco del Duratón (Segovia)". Altamira Symposium, págs. 505-526.

Llanos, A. (1989ep.): «Excavaciones en la cavidad de Solacueva de Lacozmonte (Jócano. Álava). Campañas de 1980-1981".

MaRTin VALLS, R. (1973): “Insculturas del castro salmantino de Yecla de Yeltes: nuevos hallazgos y problemas cronológicos", BSAA, XXXIX, pág. 81-103.

- (1983): “Las insculturas del castro salmantino de Yecla de Yeltes y sus relaciones con los petroglifos gallegos", Zephyrus, XXXVI, págs. 217-231

Minguez Álvaro, M. T.; Ramirez Diéz, M. J., y Ugarte Orue, M. I. (1985-86): "Pinturas rupestres esquemáticas de la Cueva de los Burros (Camasobres, Palencia)», Kobie, XV, págs. 6185

Moure Romanillo, J. A., y Garcia-Soto, E. (1986): "Los grabados de la Cueva de San Gatcia (Santo Domingo de Silos, Burgos)", Numantia II, págs. 193-213

Municio Gonzalez, L., y Piñon Varela, F. (1986-87): "Programa de documentación y estudio de la Cueva de Los Enebralejos (Prádena, Segovia)", Bajo Aragón. Prehistoria, VII-VIII, págs. 133-146.

- (1990): "Cueva de Los Enebralejos (Prádena, Segovia)", Numantia III, págs. 51-76

Municio Gonzalez, L., y Zamora Canellada, A. (1989): “Notas sobre grabados y pinturas asociados a necrópolis colectivas calcoliticas: Ios conjuntos de las cuevas de Los Enebralejos y de La Vaquera (Segovia)". Trabajos de Prehistoria, 46, págs. 271-278.

Nieto Gallo, G. (1984): Las primeras copias de pinturas rupestres esquemáticas en España. 1783. Estudios y Monografías. 11. Museo de Ciudad Real. 
- (1985): “La Península Ibérica al final del \# y comienzos del I milenio antes de Cristo hasta la aparición del Hierro", en Historia General de España y América: Los origenes de España, t. I. 1. Madrid, Ed. Rialp, págs. 429-500.

Ortega Martinez, A. I., y Martin Merino, M. A. (1986): "La arqueologia del Karst de Ojo Guareña", Kaite, 4-5. Burgos, págs. 331-389.

Ortego Frias, T. (1951): "Las estaciones de arte rupestre en el Monte Valonsadero de Soria", Celtiberia, 2, págs. 275-305.

Pérez Paredes, C., y Santos Estevez. M. (1987): "Grabados rupestres no Concello de Arbo". Castrelos $1 / 2$, págs $51-80$.

Ripoll Perelló, E. (1968): "Cuestiones en torno a la cronología del arte rupestre postpaleolitico en la Peninsula Ibérica», en (E. Ripoll, ed) Symposium Internacional de Arte Rupestre. Barcelona, 165-192.

- (1981): "Los grabados rupestres del Puntal del Tio Garrillas (términos de Pozondón. Teruel)", Revista Teruel, 66, págs. 147-155.

- (1990): "Algunos problemas del Arte Rupestre Postpaleolítico en la Península lbérica". en Arte Prehistórico de la Provincia de Soria. Museo Numantino. págs. 79-94.

SeVIllano San José. M. ${ }^{a}$ C. (1985): "Grabados rupestres en la comarca de Las Hurdes (Cáceres)", Serie resúmenes de Tesis Doctorales. Universidad de Salamanca.

Teres NavarRo, E. (1987): "Pinturas rupestres en El Raso de Candelada. Avila”, en Revista de Arqueologia núm. 74 (junio 1987), págs. 60-61.

Uribaral, J., y Liz, C. (1973): “El arte rupestre de Ojo Guareña. La Cueva de Kaite». Trabajos de Prehistoria, 30, págs. 69-120. 